\title{
As abelhas do gênero Xylocopa Latreille (Xylocopini, Apidae) do Estado de São Paulo, Brasil
}

\author{
Paola Marchi ${ }^{1,2}$ \& Isabel Alves-dos-Santos ${ }^{I}$ \\ ${ }^{1}$ Laboratório de Abelhas, Departamento de Ecologia, Instituto de Biociências, \\ Universidade de São Paulo - USP, CEP 05558-900, São Paulo, SP, Brasil \\ ${ }^{2}$ Autor para correspondência: Paola Marchi, e-mail: pmarchi@usp.br
}

MARCHI, P. \& ALVES-DOS-SANTOS, I. The bees of the genus Xylocopa Latreille (Xylocopini, Apidae) of São Paulo State, Brazil. Biota Neotrop. 13(2): http://www.biotaneotropica.org.br/v13n2/en/abstract?identificationkey+bn00913022013

\begin{abstract}
This study contributes to the knowledge about the diversity of bees belonging to the genus Xylocopa Latreille, 1802 of the São Paulo State through a compilation of taxonomic and biological information. Identification keys are presented for the four subgenera (Dasyxylocopa Hurd \& Moure, 1963; Neoxylocopa Michener, 1954; Schonnherria Lepeletier, 1841 and Stenoxylocopa Hurd \& Moure, 1960) and for the 22 species recorded for the state, beyond the available data on its biology, plants visited and geographic occurrence.

Keywords: carpenter bees, floral sources, geographic records, Hymenoptera, taxonomy.

MARCHI, P. \& ALVES-DOS-SANTOS, I. As abelhas do gênero Xylocopa Latreille (Xylocopini, Apidae) do Estado de São Paulo, Brasil. Biota Neotrop. 13(2): http://www.biotaneotropica.org.br/v13n2/pt/ abstract?identification-key+bn00913022013

Resumo: Este estudo contribui para o conhecimento da diversidade das abelhas pertencentes ao gênero $X y$ locopa Latreille, 1802 do Estado de São Paulo através de uma compilação de informações taxonômicas e biológicas. São apresentadas chaves de identificação para os quatro subgêneros (Dasyxylocopa Hurd \& Moure, 1963; Neoxylocopa Michener, 1954; Schonnherria Lepeletier, 1841 e Stenoxylocopa Hurd \& Moure, 1960) e para as 22 espécies registradas para o Estado, além dos dados existentes sobre sua biologia, plantas visitadas e ocorrência geográfica. Palavras-chave: mamangavas, fontes florais, registros geográficos, Hymenoptera, taxonomia.
\end{abstract}




\section{Introdução}

As abelhas do gênero Xylocopa Latreille, 1802, conhecidas como mamangavas, estão presentes na maioria dos continentes, predominantemente nos trópicos, subtrópicos e nas áreas mais quentes das regiões temperadas (Hurd \& Moure 1963). São conhecidas mais de 700 espécies, das quais 50 ocorrem no Brasil (Hurd 1978, Silveira et al. 2002, Moure 2008).

De acordo com Schrottky (1902) "a esse gênero pertencem as máximas abelhas", pois são abelhas grandes e robustas. Como se trata do único gênero da tribo Xylocopini, os caracteres que definem tribo e gênero são os mesmos: a cabeça tão larga quanto o mesossoma, o clípeo praticamente plano, os escapos mais longos que o segundo e terceiro flagelômeros juntos, as asas anteriores com três células submarginais, estigma ausente, preestigma e célula marginal muito longos, porções distais das asas fortemente papiladas, metassoma alongado e achatado, entre outros (Silveira et al. 2002, Michener 2007).

A maioria das espécies é solitária ou facultativamente social e constrói ninhos em madeira morta, ramos ou em cavidades de bambu, frequentemente agregados (Hurd \& Moure 1963, Sakagami \& Laroca 1971, Camillo \& Garófalo 1982, Camillo et al. 1986, Gerling et al. 1989, Marchi \& Melo 2010, Pereira \& Garófalo 2010). Algumas espécies também nidificam em escapos florais e outras partes vivas de árvores (Hurd 1978, Silveira 2002, Viana et al. 2002, Ramalho et al. 2004).

Essas abelhas exibem um comportamento generalista, visitam flores de diversas famílias botânicas e são capazes de vibrar, extraindo o pólen de flores com anteras poricidas como Solanum, Cassia, Senna, Chamaecrista e Tibouchina (Buchmann 1983). Podem atuar como polinizadoras efetivas de plantas nativas e de cultivos de interesse econômico. Destaca-se, por exemplo, o seu papel na polinização do maracujá devido a boa adequação de seu tamanho às flores de Passiflora (Nishida1963, Ruggiero et al. 1976, Corbet \& Willmer 1980, Gerling et al. 1989, Sazima \& Sazima 1989, Varassin \& Silva 1999, Camillo 2003, Melo et al. 2005, Silva et al. 2010).

Contudo, o conhecimento taxonômico das abelhas pertencentes ao gênero Xylocopa é essencial para os estudos relacionados à sua conservação e para o uso sustentável dos seus serviços de polinização.

O Estado de São Paulo, localizado no sudeste do Brasil, entre as regiões tropical e subtropical, apresenta uma grande diversidade topográfica e climática, que inclui áreas de transição de dois grandes biomas: Mata Atlântica e Cerrado, com distintos ecossistemas e enorme riqueza biológica.

Em relação ás abelhas, no domínio da Mata Atlântica, no leste e sul do Estado, é possível encontrar espécies que jamais foram coletadas em levantamentos em outros domínios (Gonçalves \& Brandão 2008), mas o conhecimento sobre a fauna de abelhas das regiões central e oeste de São Paulo é muito escasso (ImperatrizFonseca et al. 2011).

Este estudo apresenta informações taxonômicas sobre as espécies paulistas de Xylocopa, as quais estavam fragmentadas em trabalhos como o de Smith (1853, 1874), Schrottky (1902), Maild (1912), Cockerell (1912), Enderlein (1913), Moure (1949, 2008), Michener (1954), Hurd \& Moure (1963), Hurd (1978), Pedro \& Camargo (1999), Silveira et al. (2002), Schlindwein et al. (2003) e muitos levantamentos realizados no Estado. São apresentadas diagnoses com os principais caracteres que distinguem as espécies, chaves para identificação dos subgêneros e espécies de ocorrência conhecida no Estado, registros geográficos e aspectos da sua biologia para possibilitar sua identificação, uma vez que essas abelhas são frequentes nos estudos brasileiros.

\section{Material e Métodos}

Foram examinadas as abelhas depositadas nas seguintes instituições: Coleção Entomológica Paulo Nogueira Neto (CEPANN-IBUSP), Coleção Camargo, Departamento de Biologia da Faculdade de Filosofia, Ciências e Letras de Ribeirão Preto, USP (RPSP), Museu de Zoologia da Universidade de São Paulo, São Paulo (MZSP), que também forneceram os dados sobre a distribuição das espécies no Estado; foram também incluídos os registros de ocorrência em outras regiões compiladas de Hurd (1978) e Moure (2008), assim como o catálogo das espécies. As chaves de identificação foram baseadas no exame dos espécimes e informações obtidas em outros trabalhos conforme indicado no texto para cada uma das espécies. Chaves para fêmeas e machos foram elaboradas separadamente, exceto para o subgênero Neoxylocopa, cujos machos são muito semelhantes e não foi observado material suficiente para uma possível associação entre os sexos para todas as espécies, como espécimes coletados no mesmo ninho por exemplo. As informações sobre as visitas às flores são restritas ao Estado de São Paulo, obtidas em trabalhos de levantamentos regionais, estudos de polinização, informações de etiquetas dos exemplares examinados e de observações pessoais. As coordenadas geográficas aproximadas foram obtidas no sítio do IBGE, na internet e os mapas foram projetados no programa Arcview Gis (ESRI 2006). As imagens de alta resolução foram obtidas através do sistema Automontage Leica ${ }^{\circledR}$ M205C do Laboratório de Hymenoptera do MZSP, usando as lentes objetivas Planapo $2.0 \times$ e $1.0 \times$, de acordo com o tamanho do indivíduo. Quando necessário, após a obtenção das imagens, foram feitos pequenos retoques para que os detalhes ficassem mais evidentes, e para uma melhor visualização do espécime como um todo, sempre mantendo o máximo de originalidade às imagens obtidas do Automontage. O programa utilizado para os retoques necessários foi o Adobe Photoshop CS5 ${ }^{\circledR}$ da Microsoft. No texto e nas chaves foram utilizadas as abreviações: E (esterno) e T (tergo). O grádulo, segundo Hurd \& Moure (1963), é uma linha transversal impressa, geralmente localizada ventralmente na parte exposta do tergo que está sempre presente em T1, nos demais tergos se localiza perto da base, na parte sobreposta pelo tergo anterior, sendo necessário expor esta área basal para determinar sua presença ou ausência.

\section{Resultados e Discussão}

O gênero Xylocopa é bem representado no Estado de São Paulo. Pedro \& Camargo (1999) listaram 21 espécies e Moure (2008) registrou 20 espécies, pertencentes a cinco subgêneros. A partir da nova classificação subgenérica proposta por Minckley (1998), seguida por Silveira et al. (2002) e Michener (2007), o subgênero Megaxylocopa Olivier, 1789 foi incluído em Neoxylocopa e Ioxylocopa Hurd \& Moure, 1963, em Schonnherria. Assim, neste estudo foram considerados os registros de ocorrência de 22 espécies e quatro subgêneros, sendo a maioria pertencente aos subgêneros Neoxylocopa e Schonnherria (Tabela 1).

As espécies mais coletadas depositadas nas coleções consultadas foram X. (Neoxylocopa) frontalis (Olivier, 1789), X. (Neoxylocopa) brasilianorum (Linnaeus,1767), X. (Neoxylocopa) suspecta Moure \& Camargo, 1988 e X. (Stenoxylocopa) artifex Smith, 1874.

Para justificar as diferenças entre o número de espécies mostrado na Tabela 1, um espécime coletado no município de Cajuru, presente na lista das abelhas que ocorrem no Estado de São Paulo por Pedro \& Camargo (1999) foi equivocadamente identificado como $X$. (Neoxylocopa) carbonaria Smith, 1854. Neste estudo o mesmo foi examinado e identificado como X. (Schonnherria) subcyanea Pérez, 1901. 
Tabela 1. Espécies de Xylocopa registradas para o Estado de São Paulo no presente estudo e outras compilações.

Table 1. Xylocopa species recorded for the São Paulo State in the present study and other summaries.

\begin{tabular}{|c|c|c|c|}
\hline Espécie & Pedro \& Camargo (1999) & Moure (2008) & Este estudo \\
\hline Xylocopa (Dasyxylocopa) bimaculata Friese, 1903 & $\mathrm{X}$ & $\mathrm{X}$ & $\mathrm{X}$ \\
\hline Xylocopa (Neoxylocopa) augusti Lepeletier, 1841 & $\mathrm{X}$ & $\mathrm{X}$ & $\mathrm{X}$ \\
\hline Xylocopa (Neoxylocopa) brasilianorum (Linnaeus, 1767) & $\mathrm{X}$ & $\mathrm{X}$ & $\mathrm{X}$ \\
\hline Xylocopa (Neoxylocopa) carbonaria Smith, 1854 & $\mathrm{X}$ & & \\
\hline Xylocopa (Neoxylocopa) frontalis (Olivier, 1789) & $\mathrm{X}$ & $\mathrm{X}$ & $\mathrm{X}$ \\
\hline Xylocopa (Neoxylocopa) grisescens Lepeletier, 1841 & $\mathrm{X}$ & $\mathrm{X}$ & $\mathrm{X}$ \\
\hline Xylocopa (Neoxylocopa) hirsutissima Maidl, 1912 & $\mathrm{X}$ & $\mathrm{X}$ & $\mathrm{X}$ \\
\hline Xylocopa (Neoxylocopa) ordinaria Smith, 1874 & $\mathrm{X}$ & & $\mathrm{X}$ \\
\hline Xylocopa (Neoxylocopa) nigrocincta Smith, 1854 & & $\mathrm{X}$ & $\mathrm{X}$ \\
\hline Xylocopa (Neoxylocopa) rotundiceps Smith, 1874 & & $\mathrm{X}$ & $\mathrm{X}$ \\
\hline Xylocopa (Neoxylocopa) suspecta Moure \& Camargo, 1988 & $\mathrm{X}$ & $\mathrm{X}$ & $\mathrm{X}$ \\
\hline Xylocopa (Schonnherria) chrysopoda Schrottky, 1901 & $\mathrm{X}$ & $\mathrm{X}$ & $\mathrm{X}$ \\
\hline Xylocopa (Schonnherria) dimidiata Latreille, 1809 & $\mathrm{X}$ & $\mathrm{X}$ & $\mathrm{X}$ \\
\hline Xylocopa (Schonnherria) macrops Lepeletier, 1841 & $\mathrm{X}$ & $\mathrm{X}$ & $\mathrm{X}$ \\
\hline Xylocopa (Schonnherria) muscaria (Fabricius, 1775) & $\mathrm{X}$ & $\mathrm{X}$ & $\mathrm{X}$ \\
\hline Xylocopa (Schonnherria) pulchra Smith, 1854 & $\mathrm{X}$ & $\mathrm{X}$ & $\mathrm{X}$ \\
\hline Xylocopa (Schonnherria) simillima Smith, 1854 & $\mathrm{X}$ & $\mathrm{X}$ & $\mathrm{X}$ \\
\hline Xylocopa (Schonnherria) splendidula Lepeletier, 1841 & $\mathrm{X}$ & $\mathrm{X}$ & $\mathrm{X}$ \\
\hline Xylocopa (Schonnherria) subcyanea Pérez, 1901 & $\mathrm{X}$ & $\mathrm{X}$ & $\mathrm{X}$ \\
\hline Xylocopa (Schonnherria) varians Smith, 1874 & $\mathrm{X}$ & $\mathrm{X}$ & $\mathrm{X}$ \\
\hline Xylocopa (Stenoxylocopa) artifex Smith, 1874 & $\mathrm{X}$ & $\mathrm{X}$ & $\mathrm{X}$ \\
\hline Xylocopa (Stenoxylocopa) nogueirai Hurd Junior \& Moure, 1960 & $\mathrm{X}$ & $\mathrm{X}$ & $\mathrm{X}$ \\
\hline
\end{tabular}

Já as espécies do subgênero Neoxylocopa, X. nigrocincta Smith, 1854 (coletada em Jaboticabal) e $X$. rotundiceps Smith, 1879 (de Cajuru e Ribeirão Preto), também ausentes na lista de Pedro \& Camargo (1999) foram examinadas e identificadas na coleção Camargo (RPSP, USP).

De acordo com Hurd (1978) e Silveira et al. (2002) o subgênero Neoxylocopa precisa urgentemente de uma revisão. Neste contexto estão as espécies $X$. ordinaria Smith, 1874 e $X$. suspecta, as quais são muito semelhantes morfologicamente e podem apresentar sobreposição geográfica.

Xylocopa (Dasyxylocopa) Hurd \& Moure, 1963

Xylocopa (Dasyxylocopa) bimaculata Friese, 1903

\section{Diagnose:}

Este subgênero monotípico é semelhante ao subgênero Schonnherria, distinguindo-se deste pelos grádulos dos tergos: as fêmeas apresentam grádulo de T1, T3 e T4 e os machos, em T1 e de T3 a T5, enquanto que em Schonnherria, o grádulo é presente apenas em T1 nas fêmeas e nos machos, se presente, apenas em T1, e no caso de $X$. chrysopoda Schrottky, 1902, em T3 e T4. Além disso, é o único subgênero Neotropical com o corpo densamente piloso. Fêmeas com corpo de tamanho médio, um pouco alongado e robusto. Integumento preto e levemente metálico. Pilosidade preta e esbranquiçada na cabeça e mesossoma, preta no metassoma, com pelos amarelados nas laterais dos últimos tergos (T5 e T6). Os machos apresentam corpo pequeno, com manchas amareladas na mandíbula, labro, clípeo, áreas paraoculares e escapo. Pilosidade preta, com pelos amarelados na parte ventral do corpo, principalmente no mesossoma e lado externo dos tarsos, mais evidentes nos últimos tarsômeros (Hurd \& Moure 1963). Espécie rara nas coleções consultadas.

\section{Distribuição:}

Região Neotropical: ARGENTINA; BRASIL (Goiás, Paraná, Rio Grande do Sul, Rio de Janeiro, Santa Catarina, São Paulo: Campos do Jordão) (Figura 1); PARAGUAI.

\section{Notas biológicas:}

Pouco se conhece sobre sua biologia. No Estado do Rio Grande do Sul, estas abelhas foram encontradas por Hoffmann (1995) visitando flores de Phaseolus vulgaris e Schlindwein et al. (2003) observou outras plantas visitadas por esta espécie, incluindo Passiflora caerulea (Passifloraceae). O comportamento territorial dos machos de X. bimaculata e suas secreções glandulares foram observados por Schlumpberger \& Wittmann (2000). Em relação aos seus hábitos de nidificação nada se conhece.

\section{Datas de coleta:}

Fevereiro de 1964 (fêmea de Campos do Jordão).

Xylocopa (Neoxylocopa) Michener, 1954

\section{Diagnose:}

Este subgênero contém abelhas de tamanho médio e grande, as fêmeas apresentam o integumento preto, às vezes com faixas ferrugíneas no metassoma, e nos machos, predominantemente amarelo ou alaranjado. Os machos das diferentes espécies são muito semelhantes, dificultando a associação entre os sexos, exceto quando são coletados no mesmo ninho. Nas fêmeas o ápice da mandíbula é bidenteado, uma crista acompanha a sutura epistomal, as margens laterais do clípeo são elevadas e lisas, uma forte carena longitudinal mediana atravessa todos os esternos do metassoma.

É o subgênero mais diverso e amplamente distribuído nas Américas, contém 49 espécies (Moure 2008). No Brasil, Silveira et al. (2002) listaram 20 espécies, das quais 9 têm registro de ocorrência no Estado de São Paulo: X. (Neoxylocopa) augusti Lepeletier, 1841; X. (Neoxylocopa) brasilianorum (Linnaeus, 1767); X. (Neoxylocopa) 


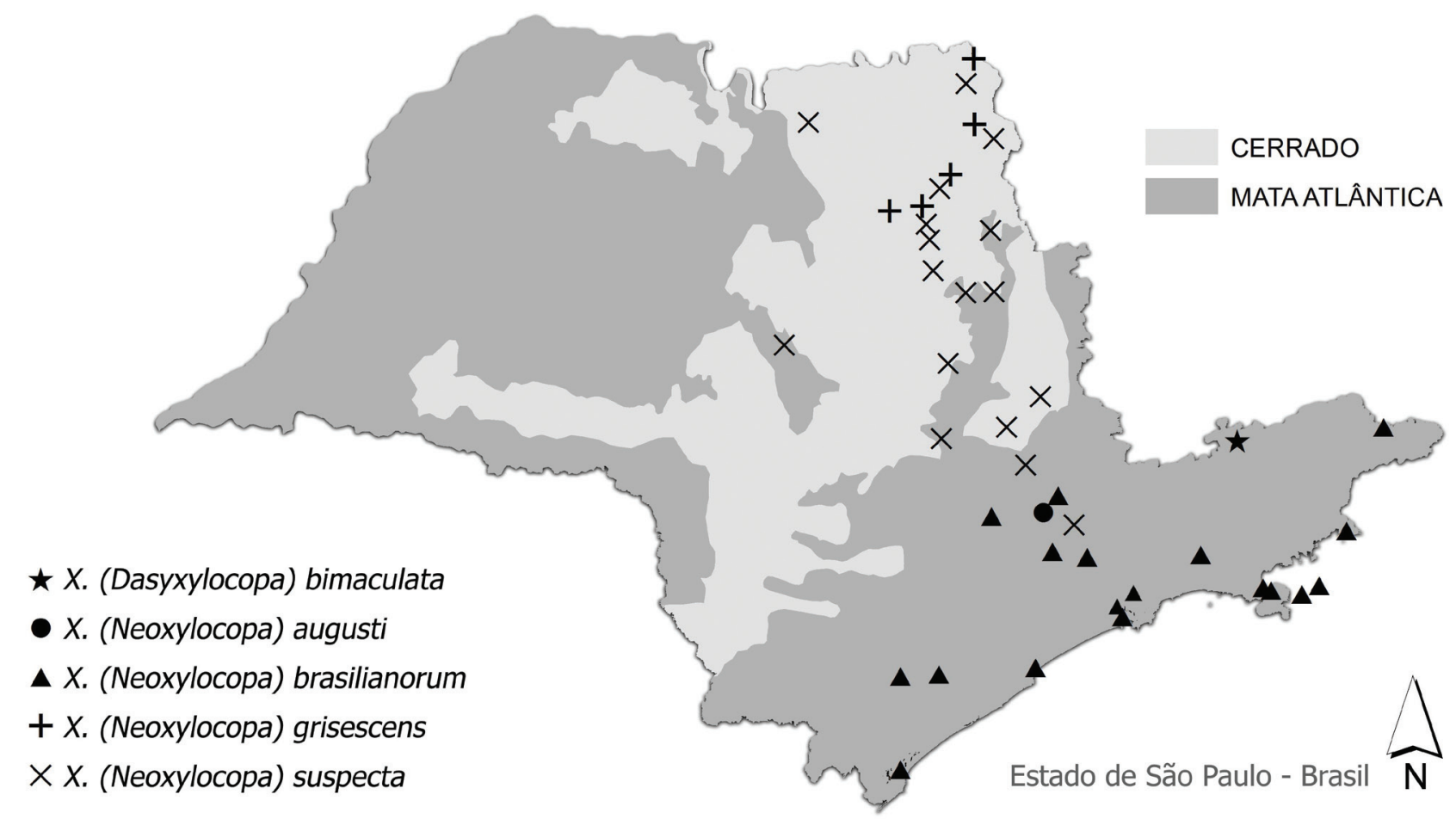

$\star X$. (Dasyxylocopa) bimaculata

- $X$. (Neoxylocopa) augusti

A X. (Neoxylocopa) brasilianorum

$+X$. (Neoxylocopa) grisescens

$X X$. (Neoxylocopa) suspecta

Figura 1. Registros de ocorrência das espécies de Xylocopa no Estado de São Paulo, Brasil.

Figure 1. Records of occurrence of the species of Xylocopa in the São Paulo State, Brazil.

frontalis (Olivier, 1789); X. (Neoxylocopa) grisescens Lepeletier, 1841; X. (Neoxylocopa) hirsutissima Maidl, 1912; X. (Neoxylocopa) ordinaria Smith, 1874; X. (Neoxylocopa) nigrocincta Smith, 1854; $X$. (Neoxylocopa) rotundiceps Smith, 1874; X. (Neoxylocopa) suspecta Moure \& Camargo, 1988. Hurd (1978) e Silveira et al. (2002) apontaram a necessidade da realização de uma revisão deste subgênero.

\section{Distribuição:}

Região Neártica: MÉXICO; ESTADOS UNIDOS DA AMÉRICA. Região Neotropical: ARGENTINA; BOLÍVIA; BRASIL (Acre, Alagoas, Amapá, Amazonas, Bahia, Ceará, Espírito Santo, Goiás, Maranhão, Mato Grosso, Mato Grosso do Sul, Minas Gerais, Paraná, Paraiba, Pará, Pernambuco, Piaui, Rio Grande do Norte, Rio Grande do Sul, Rio de Janeiro, Rondônia, Santa Catarina, Sergipe, São Paulo); CHILE; COLÔMBIA; COSTA RICA; CUBA; EQUADOR; GUADALUPE; GUATEMALA; GUIANA FRANCESA; GUIANA; HONDURAS; ILHAS GALÁPAGOS; ILHAS DO CARIBE; JAMAICA; MÉXICO; NICARAGUA; PANAMÁ; PARAGUAI; PERU; PORTO RICO; SURINAME; TRINIDAD E TOBAGO; URUGUAI; VENEZUELA. Região Oriental: HAVAÍ; ILHAS MARIANAS.

Xylocopa (Neoxylocopa) augusti Lepeletier, 1841

\section{Diagnose:}

Abelhas grandes, comprimento em torno de $27 \mathrm{~mm}$. Fêmeas com integumento preto; pilosidade preta, metassoma com pelos ferrugíneos nas laterais a partir de T2 e no ápice. Asas com brilho metálico verde-azulado. Machos com comprimento entre 26 a $28 \mathrm{~mm}$; com integumento ferrugíneo; pilosidade amarela, no metassoma mais densa que em $X$. brasilianorum, escondendo um pouco as faixas escuras do integumento e dois tufos de pelos na parte ventral da tíbia posterior.
Distribuição:

Região Neotropical: ARGENTINA; BRASIL (Goiás, Paraná, Rio Grande do Sul, Santa Catarina, São Paulo: Jundiaí) (Figura 1); PARAGUAI; URUGUAI.

\section{Notas biológicas:}

As abelhas desta espécie nidificam em madeira morta ou em ramos secos de árvores vivas. De acordo com Hurd \& Moure (1963), exibem certa preferência por mourões de cercas. Um ninho de $X$. augusti foi encontrado num mesmo tronco contendo ninhos ativos de $X$. frontalis e $X$. hisurtissima (Hurd \& Moure 1961). Sakagami \& Laroca (1971) descreveram a arquitetura dos ninhos desta espécie e observaram que as fêmeas fecham a entrada dos seus ninhos com seu metassoma quando perturbadas, assim como $X$. frontalis $\mathrm{e} X$. grisescens. Existe registro de visita às flores de Passiflora edulis (Hurd 1978). No Rio Grande do Sul, estas abelhas foram encontradas visitando flores de Phaseolus vulgaris (Hoffmann 1995). Na Argentina, a partir de análise de pólen contido nos ninhos de X. augusti, Tellería (1999) observou que as fontes mais importantes deste recurso foram as plantas das seguintes famílias: Amaryllidaceae, Asteraceae, Caprifoliaceae, Fabaceae, Myrtaceae e Solanaceae. No entanto, para São Paulo não foi encontrado nenhum registro de visitas às flores.

Datas de coleta:

O único exemplar amostrado no Estado de São Paulo só apresentou dados sobre o local de coleta: Jundiaí.

\section{Xylocopa (Neoxylocopa) brasilianorum (Linnaeus, 1767)}

\section{Diagnose:}

Xylocopa brasilianorum foi a primeira espécie de Xylocopa descrita do Novo Mundo, mas como sua descrição foi baseada em um macho, este nome foi incorretamente aplicado para várias espécies de Neoxylocopa com grande extensão geográfica. Essas abelhas possuem tamanho corporal em torno de 20 a $26 \mathrm{~mm}$; 
um dente interno na mandíbula. Fêmea com integumento preto; pilosidade preta; mesoscuto e T1 com pelos plumosos, T2 a T6 com pelos finos e longos no disco, mais densos nas laterais dos tergos. Asas transparentes, com brilho cúpreo-purpúreo, mais cúpreo no ápice. O macho é ferrugíneo; clípeo e parte dorsal do escapo amarelados; margem apical dos tergos fuscas; coxas e fêmures pretos. Um ginandromorfo de $X$. brasilianorum, apresentando os caracteres sexuais distribuídos pelo corpo em forma de mosaico foi descrito baseado em um espécime coletado em Jundiaí, SP. (F. Vivallo \& P. Marchi, dados não publicados).

\section{Distribuição:}

Região Neotropical: Brasil (Bahia, Espírito Santo, Minas Gerais, Paraná, Rio Grande do Sul, Rio de Janeiro, Santa Catarina, São Paulo: Barueri, Campinas, Cubatão, Ilhabela (Bonete, Ilha de Vitória, Ilha dos Búzios), Itu, Jundiaí, Juquiá, Paranapiacava, Peruíbe, Picinguaba, Salesópolis, São José do Barreiro, São Paulo, São Sebastião, São Vicente, Sete Barras) (Figura 1).

\section{Notas biológicas:}

Os ninhos desta espécie ocorrem em madeira morta. Uma descrição precisa da arquitetura do ninho foi apresentada por Sakagami \& Laroca (1971). Em Morretes, Paraná, fêmeas de $X$. brasilianorum fundaram ninhos entre dezembro de $2006 \mathrm{e}$ fevereiro de 2007. A maioria dos ninhos se encontrava na parte inferior do substrato e apresentaram o orifício de entrada em torno de $110 \mathrm{~mm}$. Neste local, fêmeas de $X$. frontalis utilizaram o início de escavação de $X$. brasilianorum. Um dos ninhos foi fundado em um ramo seco de araucária próximo a uma agregação de ninhos de $X$. frontalis, sob um galpão na borda da mata. Durante a escavação do ninho, a fêmea de $X$. brasilianorum realizou poucos vôos, provavelmente para se alimentar, retornando ao ninho sem pólen no corpo. Duas semanas depois, estava aprovisionando o ninho com pólen nas escopas e desidratando néctar na entrada do ninho. Durante a desidratação, o néctar observado no aparelho bucal da fêmea era mais denso, esbranquiçado e conspícuo (Marchi \& Melo 2010). Varassin \& Silva (1999) comentaram que esta espécie, além de coletar o néctar de Passiflora alata, coleta também o pólen através da vibração da musculatura das asas. Assim, a turgidez do néctar observada durante sua desidratação poderia estar relacionada com a presença de pólen. Em Guarapari, ES, estes autores observaram que essas abelhas iniciaram suas atividades em torno das 5:30 h. Schlindwein et al. (2003) observaram machos desta espécie nas margens da mata, realizando vôos rápidos em grandes faixas ou círculos, alternando com fases nas quais ficavam pairando no ar. No Estado do Rio Grande do Sul, esta espécie ocorreu exclusivamente na Mata Atlântica. Neste estudo, além das áreas de Mata Atlântica, existem registros de ocorrência desta espécie em áreas antropizadas da cidade de São Paulo.

Flores visitadas:

Thunbergia grandiflora (Acanthaceae), Allamanda cathartica, A. schottii (Apocynaceae), Bidens segetum, Dahlia sp., Vernonia westiniana (Asteraceae), Cybistax antisyphilitica, Handroanthus chrysotrichus, H. heptaphyllus, H. impetiginosus, H. umbellatus, Jacaranda puberula (Bignoniaceae), Cannavalia picta, Chamaecrista campestris, Crotalaria vitellina, Dioclea rufescens, Inga capitata, Poincianella pluviosa, Senna affinis, Senna bicapsularis, S. multijuga, Sophora tomentosa, Swartzia oblata, S. simplex, Vigna candida (Fabaceae), Behuria semiserrata, Miconia inaegidans, Tibouchina pulchra, T. scaberrima, sebastianopolitana (Melastomataceae), Campomanesia xanthocarpa, Myrcia glabra, M. pubipetala (Myrtaceae), Fuchsia regia (Onagraceae), Passiflora alata, P. actinia, P. amethystina, P. edulis, P. miersii (Passifloraceae), Eriobotrya japonica (Rosaceae), Psychotria suterella, Psychotria suterella (Rubiaceae), Cupania oblongifolia (Sapindaceae), Solanum concinnum, S. inodorum (Solanaceae), Duranta erecta (Verbenaceae), Hemerocallis fulva (Xanthorrhoeaceae) (Gottsberger \& Silberbauer-Gottsberger 1988, Ramalho 1995, Wilms 1995, Koschnitzke \& Sazima 1997, Aguilar 1998, Bittencourt Junior 2003, Pinheiro \& Sazima 2007, Brito et al. 2010, Imperatriz-Fonseca et al. 2011).

Datas de coleta:

No Estado de São Paulo, X. brasilianorum foi coletada durante o ano, exceto no mês de julho.

\section{Xylocopa (Neoxylocopa) frontalis (Olivier, 1789)}

\section{Diagnose:}

Abelhas grandes (cerca de 30 a $36 \mathrm{~mm}$ ), fêmea com integumento preto, às vezes os três ou quatro primeiros tergos com faixas ferrugíneas; proeminências em frente a cada ocelo posterior; laterais do clípeo fortemente protuberantes; disco de T1 glabro. Asas fuscas com brilho azul escuro. Macho ferrugíneo com pilosidade amarelada, densa na cabeça, pernas, mesossoma e ápice do metassoma; mandíbulas, fêmures posteriores e margem dos tergos pretos. Asas amareladas com nervuras ferrugíneas, sem brilho azul. A associação entre os sexos é mais fácil devido ao seu grande porte. Um ginandromorfo de $X$. frontalis, apresentando os caracteres sexuais distribuídos pelo corpo em forma de mosaico foi descrito baseado em um espécime coletado em Corupá, SC. (F. Vivallo \& P. Marchi, dados não publicados).

\section{Distribuição:}

Região Neártica: MÉXICO. Região Neotropical: ARGENTINA; BOLÍVIA; BRASIL (Acre, Alagoas, Amapá, Amazonas, Bahia, Ceará, Espirito Santo, Goiás, Maranhão, Mato Grosso, Minas Gerais, Paraná, Paraíba, Pará, Rio Grande do Sul, Rio de Janeiro, Santa Catarina, São Paulo: Atibaia, Bauru, Bragança, Campinas, Cássia dos Coqueiros, Cajuru, Corumbataí, Cosmópolis, Franca, Guatapará, Guarulhos, Iguape, Ilhabela (Bonete, Cigarras, Ilha dos Búzios), Itapetininga, Itu, Jaboticabal, Jundiaí, Luís Antônio, Picinguaba, Piracicaba, Ribeirão Preto, Rifaina, Rio Claro, Salesópolis, Santa Rita do Passa Quatro, São Carlos, São Paulo, São Sebastião, Sete Barras, Teodoro Sampaio, Ubatuba) (Figura 2); COLÔMBIA; COSTA RICA; EQUADOR; EL SALVADOR; GUIANA FRANCESA; GUATEMALA; GUIANA; HONDURAS; MÉXICO; NICARAGUA; PANAMÁ; PARAGUAI; PERU; TRINIDAD E TOBAGO; URUGUAI; VENEZUELA.

\section{Notas biológicas:}

Os ninhos naturais de $X$. frontalis foram descritos por vários autores (Hurd 1978, Hurd \& Moure 1963, Sakagami \& Laroca 1971). O hábito de nidificação e atividades sazonais dessas abelhas foram estudados no interior do Estado, região de Ribeirão Preto, onde esta espécie fundou ninhos durante todo o ano, com duas estações de maior freqüência: dezembro a março e junho a setembro, ocorrendo duas ou mais gerações por ano (Camillo \& Garófalo 1982, 1989, Camillo et al.1986, Camillo 2003, Pereira \& Garófalo 2010). Em Morretes, litoral do Paraná, esta espécie foi univoltina, com um período de maior freqüência de fundação dos ninhos entre outubro e dezembro (Marchi \& Melo 2010). Os machos permanecem nos ninhos após a emergência e podem ser observados realizando atividades semelhantes às das fêmeas guardas, muitas vezes sendo expulsos posteriormente dos ninhos em que nasceram. Quando capazes de voar e se alimentar, realizaram vôos de reconhecimento e ocupam ninhos abandonados (Pereira \& Garófalo 2010). Esta espécie é abundante 


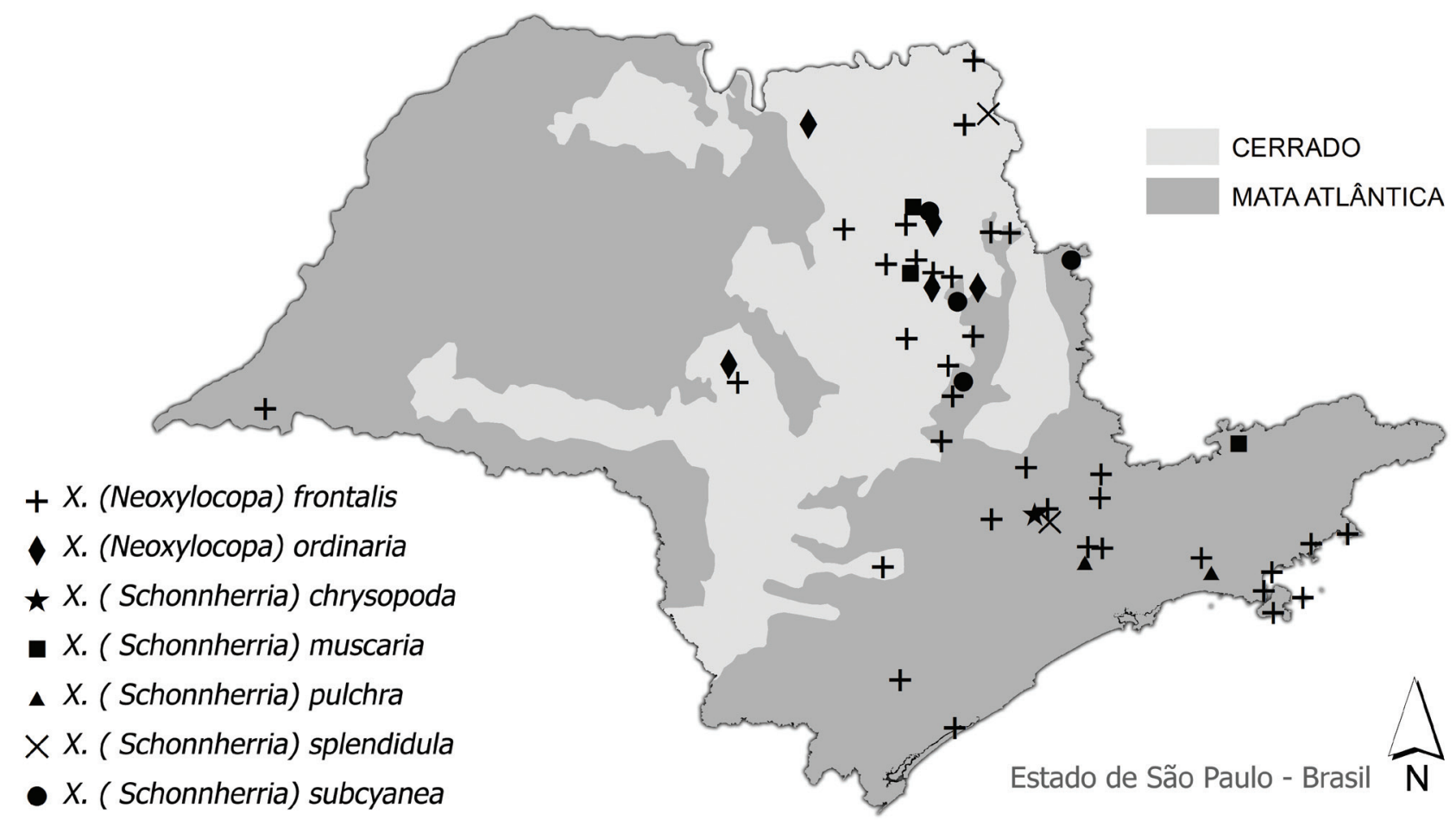

Figura 2. Registros de ocorrência das espécies de Xylocopa no Estado de São Paulo, Brasil.

Figure 2. Records of occurrence of the species of Xylocopa in the São Paulo State, Brazil.

e apresenta ampla distribuição geográfica. É uma das principais polinizadoras de Passiflora edulis f. flavicarpa (maracujá-azedo) e Passiflora alata (maracujá-doce) (Passifloraceae) por seu grande porte e abundância nos cultivos. Essas abelhas geralmente nidificam e permanecem nas áreas agrícolas, entretanto parecem já ser insuficientes para garantir a polinização natural em áreas mais antropizadas de São Paulo e outros Estados brasileiros (Camillo 2003, Oliveira Filho \& Freitas 2003). Visando a criação artificial de $X$. frontalis, Freitas \& Oliveira Filho (2001) desenvolveram um modelo de ninho semelhante à colméia Langstroth para incrementar sua população em áreas agrícolas no Estado do Ceará. Colmos de bambu também estão sendo utilizados para a atração de fêmeas e manipulação dos ninhos (Marchi \& Melo 2010, Pereira \& Garófalo 2010).

\section{Flores visitadas:}

Odontonema strictum, Thunbergia erecta, T. grandiflora (Acanthaceae), Allamanda blanchetii, A. cathartica (Apocynaceae), Schefflera vinosa (Araliaceae), Adenocalymma peregrinum, Amphilophium mansoanum, Cuspidaria pulchra, Handroanthus chrysotrichus, H. impetiginosus, H. roseo-albus Jacaranda mimosaefolia, J. puberula, Tecoma stans (Bignoniaceae), Bixa orellana, Cochlospermum vitifolium (Bixaceae), Ceiba erianthos, Eriotheca candolleana (Bombacaceae), Cordia superba (Boraginaceae), Couepia grandiflora (Chrysobalanaceae), Kielmeyera coriacea (Clusiaceae), Dichorisandra thrysiflora (Commelinaceae), Cucurbita maxima, C. moschata (Cucurbitaceae), Andira anthelmia, Bauhinia variegata, Cannavalia picta, Cassia ferruginea, C. fistula, C. grandis, C. leptophylla, C. spectabilis, Centrolobium tomentosum, Chamaecrista debilis, C. ramosa, Crotalaria junceae, C. retusa, Delonix regia, Dioclea rufescens, D. violacea, Gliricidia sepium, Machaerium angustifolium, Peltophorum dubium, Periandra mediterranea, Poincianella pluviosa, Senna affinis, S. macranthera, S. multijuga, S. pendula, S.rugosa, Stryphnodendron polyphyllum,
Swartzia oblata, S. simple, Tipuana tipu, Vigna candida (Fabaceae), Ocimum selloi (Lamiaceae), Lagerstroemia speciosa, L. indica (Lythraceae), Abelmoschus esculentus, Ceiba erianthos, Eriotheca candolleana, Hibiscus rosa-sinensis (Malvaceae), Tibouchina pulchra (Melastomastaceae), Eugenia brasiliensis, Psidium guajava (Myrtaceae), Ouratea spectabilis (Ochnaceae), Passiflora alata, $P$. actinia, P. edulis, P. gilbertii, P. nitida (Passifloraceae), Russelia equisetiformis (Plantaginaceae), Pentas lanceolata (Rubiaceae), Serjania gracilis, S. lethalis (Sapindaceae), Solanum lycocarpum, S. melongena, S. palinacanthum, S. paniculatum, S. variabile (Solanaceae), Duranta repens, Lantana fucata (Verbenaceae) (Camargo \& Mazucato 1984, Gottsberger \& Silberbauer-Gottsberger 1988, Campos 1989, Ramalho 1995, Wilms 1995, Mateus 1998, Forni-Martins et al. 1998, Manente-Baestieri \& Machado 1999, Vitali-Veiga et al.1999, Dutra \& Machado 2001, Almeida 2002, Malerbo-Souza et al. 2002, Pereira 2002, Agostini \& Sazima 2003, Andena et al. 2005, Del Lama \& Peruqueti 2006, Pinheiro \& Sazima 2007, Imperatriz-Fonseca et al. 2011).

Datas de coleta:

No Estado de São Paulo, X. frontalis foi coletada durante todo ano.

Xylocopa (Neoxylocopa) grisescens Lepeletier, 1841

\section{Diagnose:}

Esta espécie grande de Xylocopa (fêmeas em torno de 30 $\mathrm{mm}$ ) é facilmente reconhecida pela densa pilosidade branca no mesossoma, o disco do mesoscuto glabro e a margem posterior do vértice com pelos brancos. Metassoma com pilosidade longa e densa. Asas marrom-escuras, com brilho verde-violáceo.

\section{Distribuição:}

Região Neotropical: BRASIL (Alagoas, Amapá, Bahia, Ceará, Goiás, Maranhão, Mato Grosso, Minas Gerais, Paraíba, Pará, Pernambuco, Piauí, Rio Grande do Norte, Sergipe, São 
Paulo: Batatais, Franca, Ribeirão Preto, Rifaina, Sertãozinho) (Figura 1); PARAGUAI.

\section{Notas biológicas:}

O substrato e arquitetura de um ninho de $X$. grisescens foram examinados por Sakagami \& Laroca (1971) em um tronco de árvore muito apodrecido. Posteriormente, a biologia de nidificação foi acompanhada na região de Ribeirão Preto em outros estudos (Camillo \& Garófalo 1982, 1989, Camillo et al.1986, Camillo 2003, Pereira \& Garófalo 2010). Enquanto X. frontalis apresenta uma maior freqüência de vôos de forrageamento entre 13:00 e 14:00 horas, o pico de atividade desta espécie ocorre entre 17:00 e 18:00 horas, o que pode estar relacionado á disponibilidade de recursos florais. O comportamento de nidificação de $X$. grisescens é semelhante ao de $X$. frontalis, ambas são bivoltinas e estão entre os principais polinizadores dos cultivos de Passiflora edulis no noroeste do Estado. Visando sua utilização em programas de manejo para polinização, colmos de bambu foram utilizados como substrato alternativo para nidificação (Pereira \& Garófalo 2010).

\section{Flores visitadas:}

Dichorisandra thrysiflora (Commelinaceae), Acacia glomerosa, A. podalyriaefolia, Crotalaria juncea, C. striata, Delonix regia, Gliricidia sepium, Machaerium angustifolium, Poincianella pluviosa, Senna macranthera, S. rugosa, Tipuana tipu (Fabaceae), Lagerstroemia indica (Lythraceae), Tibouchina granulosa (Melastomastaceae), Psidium guajava (Myrtaceae), Passiflora edulis, P. gilbertii, P. nitida (Passifloraceae), Duranta repens (Verbenaceae) (Camargo \& Mazucato 1984, Malerbo-Souza 2002, Pereira 2002, Camillo 2003, Del Lama \& Peruqueti 2006).

\section{Datas de coleta:}

No Estado de São Paulo, X. grisescens foi coletada nos meses de maio, junho, agosto, outubro e novembro.

\section{Xylocopa (Neoxylocopa) hirsutissima Maidl, 1902}

\section{Diagnose:}

Fêmeas com comprimento total em torno de $22 \mathrm{~mm}$. Esta espécie é reconhecida pelas fêmeas apresentarem densa pilosidade preta e plumosa no mesossoma, densa e longa no metassoma, pelos longos na face, vértice e genas. Asas escuras com brilho violáceo na metade basal e um pouco azulado e esverdeado no ápice.

\section{Distribuição:}

Região Neotropical: BOLÍVIA; BRASIL (Goiás, Mato Grosso, Minas Gerais, Paraná, Pará, Pernambuco, Piauí, Rio de Janeiro Rondônia, São Paulo: Batatais, Cosmópolis, Luís Antônio, Pirassununga, Rio Claro, Santa Rita do Passa Quatro, São Carlos) (Figura 3); PARAGUAI.

\section{Notas biológicas:}

Um ninho desta espécie foi encontrado num mesmo tronco contendo ninhos ativos de $X$. frontalis e X. augusti (Hurd \& Moure 1961). Sakagami \& Laroca (1971) descreveram a arquitetura de seus ninhos, com diâmetro de entrada entre 14 e $15 \mathrm{~mm}$. Velthuis \& Camargo (1975a, b) observaram o comportamento de cópula de X. hirsutissima.

\section{Flores visitadas:}

Stilpnopappus speciosus (Asteraceae), Conepia grandiflora (Chrysobalanaceae), Poincianella pluviosa, Senna affinis, Senna rugosa (Fabaceae), Serjania sp. (Sapindaceae), Hybanthus communis (Violaceae) (Gottsberger \& Silberbauer-Gottsberger, 1988, Aguilar 1998, Almeida 2002, Pedro 1992, Del Lama \& Peruqueti 2006, Imperatriz-Fonseca et al. 2011).

\section{Datas de coleta:}

No Estado de São Paulo, X. hirsutissima foi coletada nos meses de janeiro, fevereiro, março, abril, junho, julho, setembro e dezembro.

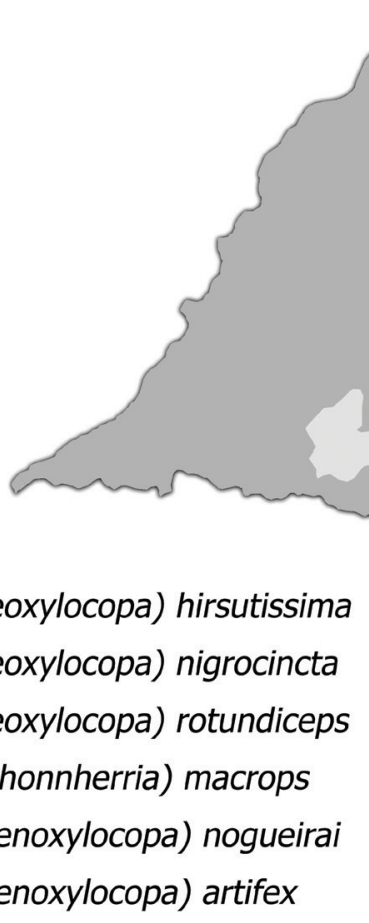

- $X$. (Neoxylocopa) hirsutissima

- X. (Neoxylocopa) nigrocincta

$\Delta X$. (Neoxylocopa) rotundiceps

$\checkmark$ X. (Schonnherria) macrops

$X X$. (Stenoxylocopa) nogueirai

+ X. (Stenoxylocopa) artifex

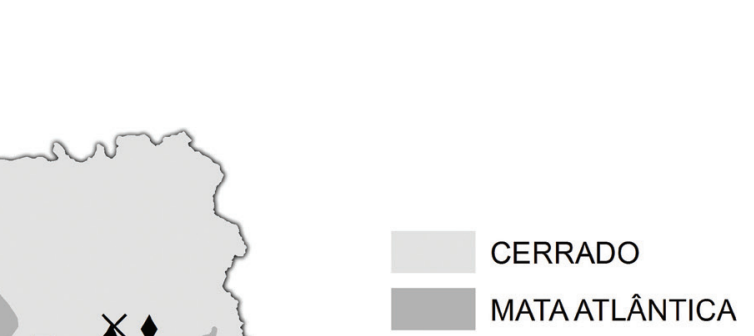

Figura 3. Registros de ocorrência das espécies de Xylocopa no Estado de São Paulo, Brasil.

Figure 3. Records of occurrence of the species of Xylocopa in the São Paulo State, Brazil. 
Xylocopa (Neoxylocopa) nigrocincta Smith, 1854

\section{Diagnose:}

Fêmea com cerca de $20 \mathrm{~mm}$; cabeça e mesossoma pretos. Metassoma ferrugíneo e densamente pontuado, com faixa preta na margem apical dos tergos; T5 escurecido; T6 preto; laterais do metassoma com pelos pretos e densos. Asas ferrugíneas escuras, com forte brilho violáceo. Lucia et al. (2009) descreveram um ginandromorfo desta espécie a partir de um exemplar de Misiones, Argentina.

\section{Distribuição:}

Região Neotropical: ARGENTINA; BRASIL (Bahia, Espírito Santo, Mato Grosso, Minas Gerais, Paraná, Rio Grande do Sul, Rio de Janeiro, Santa Catarina, São Paulo: Jaboticabal) (Figura 3); PARAGUAI.

\section{Notas biológicas:}

Sakagami \& Laroca (1971) descreveram a arquitetura de um ninho de $X$. nigrocincta do Paraguai, em madeira morta cujo diâmetro de entrada foi em torno de $12 \mathrm{~mm}$. Wittmann \& Scholz (1989) acompanharam os ninhos de X. nigrocincta em Porto Alegre, RS e observaram que, diferente dos machos de $X$. frontalis, $X$. augusti e $X$. varians que foram expulsos dos ninhos que nasceram e ocuparam ninhos abandonados, os machos de $X$. nigrocincta não deixaram seus ninhos e foram alimentados com néctar pelas fêmeas do seu ninho. Os mesmos desidrataram o néctar recebido na entrada destes ninhos antes de voar, aumentando a concentração de açúcar, diminuindo o excesso de água e prolongando seu tempo de vôo no período de acasalamento. Hoffmann (1995) encontrou estas abelhas visitando flores de Phaseolus vulgaris.

\section{Datas de coleta:}

As duas fêmeas examinadas foram coletadas no mês de abril, em Jaboticabal.

\section{Xylocopa (Neoxylocopa) ordinaria Smith, 1874}

\section{Diagnose:}

Fêmeas com aproximadamente $20 \mathrm{~mm}$; integumento preto; pilosidade preta; T1 com pilosidade plumosa, disco de T2 com pontuação densa e pelos sobrepassando o bordo dos pontos, contrastando com a margem lisa dos tergos. Asas com forte brilho violáceo, porém existe uma variação nesta coloração, podendo ser esverdeada na sua porção basal. Deste modo, esta espécie pode ser confundida com $X$. suspecta, muito semelhantes morfologicamente, e podem ocorrer nas mesmas áreas.

\section{Distribuição:}

Região Neotropical: ARGENTINA; BRASIL (Espírito Santo, Mato Grosso do Sul, Rio Grande do Sul, Rio de Janeiro, São Paulo: Bauru, Jundiaí, Luís Antônio, Monte Alegre, Ribeirão Preto, Santa Rita do Passa Quatro) (Figura 2); PERU.

\section{Notas biológicas:}

Essas abelhas são consideradas polinizadoras efetivas de Passiflora alata (Varassin \& Silva 1999) e Passiflora edulis f. flavicarpa (Hoffmann et al. 2000, Benevides et al. 2009). Os hábitos de nidificação de $X$. ordinaria foram estudados em uma área de restinga no norte do Estado do Rio de Janeiro, onde esta espécie foi multivoltina, seus ninhos naturais apresentaram distribuição agregada, com diâmetros da entrada entre 13 e $15 \mathrm{~mm}$. Além da arquitetura dos ninhos, os autores observaram as plantas visitadas e a presença do parasita Cissites maculata Swederus, 1787 (Meloidae, Coleoptera) (Bernardino \& Gaglianone 2008).

\section{Flores visitadas:}

Amphilophium mansoanum (Bignoniaceae), Chamaecrista debilis, C. desvauxii, Senna affinis, S. multijuga, S. pendula, S. rugosa (Fabaceae), Byrsonima intermedia (Malpighiaceae), Solanum inodorum, S. lycocarpum (Solanaceae) (Gottsberger \& Silberbauer-Gottsberger 1988, Campos 1989, Albuquerque 2001, Imperatriz-Fonseca et al. 2011).

\section{Datas de coleta:}

No Estado de São Paulo, X. ordinaria foi coletada nos meses de janeiro, fevereiro, março, agosto, setembro e dezembro.

Xylocopa (Neoxylocopa) rotundiceps Smith, 1874

\section{Diagnose:}

Fêmea com cerca de $22 \mathrm{~mm}$; completamente preta; pilosidade preta, exceto a parte ventral dos tarsos anteriores ferrugínea; clípeo finamente pontuado e glabro na margem anterior; vértice pontuado; pilosidade mais densa na face, genas e mesossoma, sendo o disco do mesoscuto glabro; metassoma praticamente glabro, T1 com poucos pontos e pouquíssimos pelos apenas no bordo anterior, T2 e T3 com pontuação esparsa no disco, T4 a T6 mais densamente pontuado. Asas fuscas com fraco brilho azul. Pode ser confundida com Xylocopa suspecta, diferenciando-se desta por não apresentar pilosidade plumosa no disco de T1. O macho não foi observado.

\section{Distribuição:}

Região Neotropical: ARGENTINA; BRASIL (São Paulo: Cajuru, Cosmópolis, Ribeirão Preto) (Figura 3); COLÔMBIA.

\section{Flores visitadas:}

Passiflora edulis (Passifloraceae) (P. Marchi \& I. Alves-dosSantos, dados não publicados).

\section{Datas de coleta:}

No Estado de São Paulo, duas fêmeas de Cajuru examinadas na coleção RPSP foram coletadas nos meses de janeiro e uma fêmea de Ribeirão Preto, em abril. Recentemente foi coletada uma fêmea em Cosmópolis, em janeiro.

Xylocopa (Neoxylocopa) suspecta Moure \& Camargo, 1988

\section{Diagnose:}

Fêmeas com cerca de $23 \mathrm{~mm}$; integumento preto; pilosidade preta; T1 com pilosidade plumosa, disco de T2 com pontos esparsos e pelos curtíssimos, apenas sobressaindo os pontos de insersão, mais longos e densos nas laterais; nos demais tergos pelos um pouco mais longos, porém sempre mais curtos no meio dos tergos do que nas laterais. Asas escuras com forte brilho verde metálico, às vezes com brilho violáceo próximo à margem anterior. Devido á coloração esverdeada das asas, esta espécie já foi erroneamente identificada como Xylocopa virescens Lepeletier, 1841 (Schlindwein et al. 2003). Esta espécie é muito semelhante morfologicamente à $X$. ordinaria, principalmente porque existe uma variação na coloração do brilho das asas e ambas podem ocorrer nas mesmas áreas, mas podem ser distinguidas pela pilosidade de T2.

\section{Distribuição:}

Região Neotropical: ARGENTINA; BOLÍVIA; BRASIL (Bahia, Espírito Santo, Mato Grosso, Minas Gerais, Paraíba, Pará, Pernambuco, Rio Grande do Sul, Rio de Janeiro, São Paulo: Bariri, Batatais, Brodósqui, Cajuru, Campinas, Cosmópolis, Corumbataí, Luís Antônio, Mogi Mirim, Monte Alegre, Patrocínio Paulista, Pedregulho, Piracicaba, Ribeirão Preto, Rio Claro, Tambaú, Santa Rita do Passa Quatro) (Figura 1); PARAGUAI; URUGUAI. 


\section{Notas biológicas:}

O hábito de nidificação de $X$. suspecta foi estudado na região de Ribeirão Preto (Camillo \& Garófalo 1982, 1989, Camillo et al.1986, Pereira 2002, Camillo 2003). Assim como para $X$. grisescens e $X$. frontalis, as fêmeas de $X$. suspecta utilizam bambus além de madeira morta e seca, como substrato para nidificação, sem especificidade em relação ao substrato utilizado. O diâmetro da entrada dos ninhos variou de 10 a 12 mm (Camillo 2003, Pereira \& Garófalo 2010).

\section{Flores visitadas:}

Baccharis punctulada, Helianthus annuus (Asteraceae), Pyrostegia venusta, Tecoma stans (Bignoniaceae), Kielmeyera rubriflora (Clusiaceae), Couepia grandiflora (Chrysobalanaceae), Kielmeyera rubiflora (Clusiaceae), Acosmium subelegans, Bauhinia bongardii, B. rufa, Bowdichia virgilioides, Cannavalia parviflora, C. picta, Cassia spectabilis, Centrosema sagittatum, Chamaecrista debilis, C. desvauxii, Crotalaria retusa, C. striata, Dioclea rufescens, Machaerium angustifolium, Periandra mediterranea, Senna affinis, S. pendula, S. rugosa, Stryphnodendron polyphyllum (Fabaceae), Hyptis marrubioides (Lamiaceae), Lagerstroemia speciosa (Lythraceae), Ouratea spectabilis (Ochnaceae), Oxalis physocalyx (Oxalidaceae), Passiflora edulis, P. miersii (Passifloraceae), Solanum lycocarpum, S. palinacanthum (Solanaceae), Styrax camporum (Styraceae), Qualea multiflora (Vochysiaceae) (Camargo \& Mazucato 1984; Gottsberger \& Silberbauer-Gottsberger 1988, Campos 1989, Franco 1995, Koschnitzke \& Sazima 1997, Mateus 1998, Manente-Baestieri \& Machado 1999, Vitali-Veiga et al. 1999, Almeida 2002, Pedro 1992, Pinheiro-Machado 2002, Nascimento \& Del-Claro 2007, Andena et al. 2005, Imperatriz-Fonseca et al. 2011).

Datas de coleta:

No Estado de São Paulo, X. suspecta foi coletada durante o ano, exceto no mês de junho.

Xylocopa (Schonnherria) Lepeletier, 1841

\section{Diagnose:}

Este subgênero contém espécies de tamanho pequeno a médio, a maioria é metálica e difere de outros subgêneros por apresentarem grádulo apenas em T1 nas fêmeas e nos machos, se presente, apenas em T1; no caso de X. chrysopoda, em T3 e T4. As fêmeas possuem o escutelo não modificado, ou seja, inclinado e não elevado e geralmente apresentam algumas cerdas esbranquiçadas, principalmente no mesossoma e metassoma. Os machos apresentam o clípeo esbranquiçado ou amarelo, olhos convergentes acima, chegando a quase se encontrar no vértice e tarsos levemente dilatados. Ambos os sexos apresentam o metassoma alongado e achatado (Hurd \& Moure 1963, Michener 1954, 2007). Contém 31 espécies (Moure 2008) e embora o espécie-tipo seja da região Neártica, este é o principal subgênero da região Neotropical. No Brasil, Silveira et al. (2002) listaram 19 espécies, das quais 9 ocorrem no Estado de São Paulo (incluindo Ioxylocopa Hurd \& Moure, 1963): X. chrysopoda Schrottky, 1901, X. dimidiata Latreille, 1809, X. macrops Lepeletier, 1841, X. muscaria (Fabricius, 1775), X. pulchra Smith, 1874, X. simillima Smith, 1854, X. splendidula Lepeletier, 1841, X. subcyanea Pérez, 1901, X. varians Smith, 1874.

\section{Distribuição:}

Região Neártica: MÉXICO; ESTADOS UNIDOS DA AMÉRICA; Região Neotropical: ARGENTINA; BOLÍVIA; BRASIL (Acre, Alagoas, Amapá, Amazonas, Bahia, Ceará, Espírito Santo, Goiás, Maranhão, Mato Grosso, Mato Grosso do Sul, Minas Gerais, Paraná, Paraíba, Pará, Pernambuco, Rio
Grande do Norte, Rio Grande do Sul, Rio de Janeiro, Rondônia, Santa Catarina, São Paulo); CHILE; COLÔMBIA; COSTA RICA; EQUADOR; EL SALVADOR; GUIANA FRANCESA; GUATEMALA; GUIANA; HONDURAS; JAMAICA; MÉXICO; NICARAGUA; PANAMÁ; PARAGUAI; PERU; SURINAME; TRINIDAD E TOBAGO; URUGUAI; VENEZUELA.

\section{Xylocopa (Schonnherria) chrysopoda Schrottky, 1901}

\section{Diagnose:}

Esta espécie pertencia ao subgênero monotípico Ioxylocopa, que apresenta muitas características em comum com o subgênero Schonnherria, ao qual foi incluída recentemente. Só se conhece o macho, cujos caracteres estruturais indicam uma relação próxima à Dasyxylocopa. Corpo de tamanho médio, delgado e densamente piloso. Integumento preto; manchas amareladas na mandíbula, labro, clípeo, 2/3 inferiores da área paraocular, área supraclipeal e escapo; tergos levemente metálicos. Pilosidade amarela na face, T1, T7, parte ventral do corpo e fêmur posterior. O grádulo está presente em T1 e de T3 a T5, enquanto nas demais espécies de Schonnherria, se presente, apenas em T1. Asas acastanhadas e hialinas.

\section{Distribuição:}

Região Neotropical: ARGENTINA; BRASIL (Paraná, Rio Grande do Sul, Santa Catarina, São Paulo: Jundiaí) (Figura 2).

\section{Notas biológicas:}

Nada se conhece sobre sua biologia. No Estado do Rio Grande do Sul, vários machos foram observados voando juntos em pequenas áreas ensolaradas na margem da mata em São Francisco de Paula (Schlindwein et al. 2003).

\section{Datas de coleta:}

O único exemplar amostrado no Estado de São Paulo só apresentou dados sobre o local de coleta: Jundiaí.

Xylocopa (Schonnherria) dimidiata Latreille, 1809

\section{Diagnose:}

Em relação a outras espécies de Schonnherria, são abelhas maiores. Fêmeas com tamanho corporal em torno de $20 \mathrm{~mm}$. Integumento preto e brilhante, a parte posterior do mesossoma e tergos verdes. Pilosidade preta em todo o corpo, longa e densa na face, clípeo, áreas paraoculares e vértice, curta e densa ao redor do disco do mesoscuto e alguns pelos longos no disco do escutelo, mais densos no bordo posterior. Genas com poucos pontos esparsos; T1 a T3 com pontos esparsos e pelos curtos no disco, um pouco mais longos e densos a partir de T4. Asas com brilho violeta. Os machos apresentam os olhos muito aproximados no vértice, o mesossoma e metassoma com brilho azul-esverdeado e pilosidade predominantemente preta, apenas T2, T3 e T4 com pilosidade amarelada. Asas posteriores acastanhadas, com fraco brilho violeta.

Distribuição:

Região Neotropical: ARGENTINA; BOLÍVIA; BRASIL (Amazonas, Mato Grosso, Pará, São Paulo); CHILE; COLÔMBIA; PANAMÁ; PARAGUAI; PERU; SURINAME; VENEZUELA.

\section{Datas de coleta:}

Não foram observados exemplares amostrado no Estado de São Paulo. A diagnose dos machos foi elaborada com base na literatura.

\section{Xylocopa (Schonnherria) macrops Lepeletier, 1841}

\section{Diagnose:}

Fêmeas: abelhas médias, com integumento preto, com brilho azul pouco perceptível; pilosidade preta; genas com pontos 
esparsos e poucos pelos pretos; disco do metassoma praticamente glabro, T1 com pelos esparsos na margem anterior; T5 e T6 com cerdas brancas nas laterais, E3 a E5 com pelos esbranquiçados nas laterais; tergos sem faixas integumentares ferrugíneas. Asas fuscas com brilho violeta. Machos com mancha branco-amarelada no labro, na face até as antenas, lado ventral do escapo, laterais de E3 a E5 com manchas triangulares da mesma cor. Face e genas com pilosidade branca, no vértice, preta. Tíbias anteriores, posteriores e tarsos anteriores com pilosidade branco-amarelada. Escutelo, faixa transversal de T1 e laterais do último tergo com pelos brancos. Metassoma com brilho azul ou verde, parte ventral azul, com pilosidade branca. Asas vítreas, amarelas nas pontas (Schrottky 1902). Assim como o macho de X. dimidiata e $X$. muscaria, o macho de $X$. macrops apresenta os olhos muito grandes, convergentes e separados dorsalmente por pequena área.

\section{Distribuição:}

Região Neotropical: ARGENTINA; BOLÍVIA; BRASIL (Amazonas, Bahia, Ceará, Espírito Santo, Goiás, Mato Grosso, Minas Gerais, Paraná, Pará, Pernambuco, Rio Grande do Sul, Rio de Janeiro, Rondônia, Santa Catarina, São Paulo: Campinas, Corumbataí, Itu, Jundiaí, Luís Antônio, Ribeirão Preto, Santa Rita do Passa Quatro) (Figura 3); COLÔMBIA; PARAGUAI; PERU.

Notas biológicas:

Conforme Schlindwein et al. (2003), foram observados ninhos de $X$. macrops em inflorescências de Eryngium. Existe registro do parasita Physocephala testacea (Conopidae, Diptera) criado no metassoma de X. macrops na Argentina (Hurd 1978).

\section{Flores visitadas:}

Cassia sp., Chamaecrista debilis, C. desvauxii, Crotalaria brachycarpa, C. paulinia, C. striata, Gliciridia sepium, Machaerium angustifolium, Senna pendula, S. rugosa, Stryphnodendron polyphyllum, (Fabaceae), Byrsonima intermedia (Malpighiaceae), Styrax camporum (Styracaceae), Vochysia tucanorum (Vochysiaceae) (Camargo \& Mazucato 1984, Gottsberger \& Silberbauer-Gottsberger 1988, Pinheiro-Machado 2002, Andena et al. 2005, Imperatriz-Fonseca et al. 2011).

\section{Datas de coleta:}

No Estado de São Paulo, $X$. macrops foi coletada durante o ano, exceto no mês de junho.

\section{Xylocopa (Schonnherria) muscaria (Fabricius, 1775)}

\section{Diagnose:}

Fêmeas pequenas; integumento preto azulado; pilosidade preta; nas genas, pilosidade branca e densa cobrindo todo o integumento. Metassoma com pelos brancos nas laterais de T5 e T6, E4 e E5 e pilosidade preta no ápice. Machos com olhos grandes, quase se encontrando no vértice, assim como $X$. dimidiata e $X$. macrops; labro e clípeo amarelados, áreas paraoculares com mancha amarelada até os soquetes antenais; pilosidade esbranquiçada nas genas, mesoscuto, pernas anteriores e posteriores, parte ventral e ápice do metassoma; T1 com pilosidade preta, T2 a T4 com pelos curtos nas laterais, $\mathrm{T} 5$ com pelos brancos e pretos e T6 com pelos brancos densos.

\section{Distribuição:}

Região Neártica: MÉXICO. Região Neotropical: BOLÍVIA; BRASIL (Alagoas, Amapá, Amazonas, Bahia, Ceará, Espírito Santo, Goiás, Maranhão, Mato Grosso, Paraná, Paraíba, Pará, Rio Grande do Norte, Rio de Janeiro, Rondônia, São Paulo: Campos do Jordão, Luís Antônio, Ribeirão Preto) (Figura 2); COLÔMBIA; COSTA RICA; EQUADOR; EL SALVADOR; GUIANA FRANCESA; GUATEMALA;
GUIANA; HONDURAS; PANAMÁ; PARAGUAI; PERU; TRINIDAD E TOBAGO; VENEZUELA.

\section{Notas biológicas:}

Na Costa Rica, durante a estação chuvosa, Sage (1968) observou que $X$. muscaria iniciava suas atividades antes do sol nascer até as primeiras horas da manhã. Essas abelhas visitaram frequentemente as flores de Solanum sp. (Solanaceae), extraindo o pólen das anteras tubulares vibrando seu corpo. Os machos mostraram um comportamento territorial, como o patrulhamento e a agressividade em relação às fêmeas.

\section{Flores visitadas:}

Cassia sp., Chamaecrista debilis (Fabaceae), Solanum lycocarpum (Solanaceae) (Nascimento \& Del-Claro 2007).

Datas de coleta:

No Estado de São Paulo, X. muscaria foi coletada nos meses de janeiro, fevereiro, setembro, novembro e dezembro.

\section{Xylocopa (Schonnherria) pulchra Smith, 1854}

\section{Diagnose:}

Fêmeas pequenas com cabeça, mesossoma e pernas pretos; flagelo com a parte ventral ferrugínea; pernas anteriores pretas, tarsos posteriores com pilosidade preta e ferrugínea na parte interna, branca no lado externo e preta no ápice; basitarsos anterior e médio com pelos pretos; metassoma verde, brilhante e finamente pontuado; T2 a T5 com faixas largas de pelos amarelos, interrompidas ao meio, cobrindo quase toda a metade exposta dos tergos; disco dos tergos com cerdas pretas, com exceção das laterais de T1. Asas hialinas com venação ferrugínea.

\section{Distribuição:}

Região Neotropical: ARGENTINA; BRASIL (Minas Gerais, Paraná, Rio Grande do Sul, Santa Catarina, São Paulo: Salesópolis, São Paulo) (Figura 2); COLÔMBIA; PARAGUAI.

Datas de coleta:

No Estado de São Paulo, X. pulchra foi coletada nos meses de agosto, setembro e novembro.

\section{Xylocopa (Schonnherria) simillima Smith, 1854}

\section{Diagnose:}

Esta espécie se assemelha a uma pequena $X$. frontalis, ambas são pretas com os três tergos basais ferrugíneos e as margens apicais pretas (Smith 1874). Fêmeas com cabeça e mesossoma pretos, mesossoma liso e brilhante, com brilho violeta; metassoma com manchas acastanhadas; asas fuscas escurecidas, com brilho violeta; pernas pretas; T1 a T3 e, às vezes, a base de T4 castanhos, com uma faixa preta nas margens apicais. Esta espécie é semelhante a $X$. nigrocincta, pertencente ao subgênero Neoxylocopa, mas pode ser reconhecida pela carena longitudinal mediana ausente ou fracamente elevada na parte ventral do metassoma. O macho é desconhecido.

\section{Distribuição:}

Região Neotropical: ARGENTINA; BOLÍVIA; BRASIL (Acre, Amazonas, Minas Gerais, Paraná, Pará, Rio Grande do Sul, Santa Catarina, São Paulo); PARAGUAI; PERÚ.

\section{Datas de coleta:}

Não foram observados exemplares amostrado no Estado de São Paulo.

\section{Xylocopa (Schonnherria) splendidula Lepeletier, 1841}

\section{Diagnose:}

Fêmeas pequenas, com aproximadamente $16 \mathrm{~mm}$, com integumento azul escuro; pilosidade preta; parte ventral do flagelo esbranquiçado; parte interna das pernas anteriores e 
ápice das outras pernas ferrugíneos. Machos com integumento azul brilhante; clípeo e labro amarelos; parte ventral das antenas acastanhadas; mesossoma com pilosidade curta e esbranquiçada; T1 com pelos brancos e pretos. Asas hialinas, com o ápice amarelo escuro.

Distribuição:

Região Neotropical: ARGENTINA; BOLÍVIA; BRASIL (Espírito Santo, Minas Gerais, Paraná, Rio Grande do Sul, São Paulo: Franca, Jundiaí) (Figura 2); CHILE; PARAGUAI; PERÚ; URUGUAI.

\section{Notas biológicas:}

Schlindwein et al. (2003) observaram que $X$. splendidula nidifica em madeira morta e entrenós de bambu. No Chile esta espécie foi encontrada construindo ninhos em ramos vivos de Acacia dealbata e Erythrina falcata (Fabaceae) (Montalva et al. 2008).

\section{Datas de coleta:}

Não foram observados exemplares amostrado no Estado de São Paulo.

\section{Xylocopa (Schonnherria) subcyanea Pérez, 1901}

\section{Diagnose:}

Fêmeas com aproximadamente $14 \mathrm{~mm}$; integumento preto na cabeça e mesossoma, azul esverdeado escuro no metassoma; margem dos esternos descolorida; tégulas pretas. Pontuação muito densa nas genas. Pilosidade preta, com alguns pelos dourados no labro, esbranquiçados nas laterais de T1e pelos brancos nas laterais de E3 e E4. Pelos geralmente plumosos na cabeça, mesossoma e laterais de T5 e T6. Asas enfumadas, com fracos reflexos cobre-violeta; venação escura. Machos com coloração semelhantes à da fêmea, com manchas esbranquiçadas no labro, base das mandíbulas, clípeo, área supraclipeal, áreas paraoculares até a tangente superior dos ocelos posteriores; parte ventral do escapo e artículo basal do flagelo; parte ventral do flagelo amarela. Pilosidade preta na face, vértice, genas, pronoto, pelos esbranquiçados na margem anterior das tégulas, mesoscuto, mesepisternos, pernas, laterais de T1 e laterais de E3 a E5. Pontuação esparsa no clípeo, área supraclipeal e paraoculares. Vértice estreito, distância entre as órbitas com pouco mais de cinco diâmetros de um ocelo. Escapo ultrapassa a tangente dos ocelos.

Distribuição:

Região Neotropical: ARGENTINA; BOLÍVIA; BRASIL (Alagoas, Bahia, Espirito Santo, Goiás, Mato Grosso, Minas Gerais, Paraná, Pará, São Paulo: Cajuru, Ribeirão Preto, Rio Claro, São José do Barreiro (Serra da Canastra), Santa Rita do Passa Quatro) (Figura 2); PARAGUAI; URUGUAI.

\section{Notas biológicas:}

As atividades junto à entrada dos ninhos de fêmeas e machos de $X$. subcyanea foram estudadas na restinga do litoral norte da Bahia. As atividades diárias dessas abelhas foram sincronizadas com os horários do nascer e pôr de sol e os machos exibiram um comportamento de territoriedade e agressividade em relação às fêmeas. A arquitetura dos ninhos foi semelhante à descrita para $X$. frontalis e $X$. grisescens (Gimenes et al. 2006).

\section{Flores visitadas:}

Stachytarpheta dichotoma (Verbenaceae) (Camargo \& Mazucato 1984).

Datas de coleta:

No Estado de São Paulo, X. . subcyanea foi coletada nos meses de julho, outubro e dezembro.
Xylocopa (Schonnherria) varians Smith, 1874

\section{Diagnose:}

Fêmeas com integumento azul escuro, com brilho esverdeado, principalmente no metassoma. Pilosidade na face esbranquiçada; genas com pelos brancos e pretos mesclados; mesossoma com pilosidade quase toda preta (escutelo com pilosidade preta e branca, tarsos com pilosidade amarelada na parte ventral); tergos com pelos predominantemente pretos; parte ventral do metassoma com pilosidade esbranquiçada. Tégulas com coloração verde-escuro metálica (Schrottky 1902, Moure 1949). Machos com mancha amarelada na parte mediana das mandíbulas, labro, clípeo, área supraclipeal, áreas paraoculares até a tangente inferior ao ocelo médio, parte ventral do escapo e do artículo basal do flagelômero. Pilosidade esbranquiçada nas genas, mesoscuto, mesepisternos, escutelo, pernas, T1, laterais emargem posterior de T2 a T5. Ápice do metassoma com pelos pretos.

\section{Distribuição:}

Região Neotropical: ARGENTINA; BOLÍVIA; BRASIL (Amazonas, Espírito Santo, Mato Grosso, Paraná, Paraíba, Rio Grande do Sul, Rio de Janeiro, Rondônia, Santa Catarina, São Paulo); PARAGUAI.

Notas biológicas:

Schlindwein et al. (2003) observaram que os machos de $X$. varians procuram ninhos abandonados na primeira saída dos ninhos que nasceram e permanecem neles durante todo o período de acasalamento, inclusive com outros machos.

\section{Datas de coleta:}

Não foram observados exemplares amostrado no Estado de São Paulo.

\section{Xylocopa (Stenoxylocopa) Hurd \& Moure, 1960}

\section{Diagnose:}

As espécies deste subgênero são pequenas, alongadas e podem ser levemente metálicas. Diferem de outras Xylocopa por apresentarem o dente superior da mandíbula mais largo que o inferior, mas as mesmas podem ser confundidas superficialmente com fêmeas de algumas espécies do subgênero Neoxylocopa. O subgênero Stenoxylocopa contém seis espécies reconhecidas, três da América do Norte (Xylocopa micheneri Hurd, 1978, X. decipiens Hurd, 1978 e X. strandi Dusmet \& Alonso, 1924) e quatro da América do Sul (X. lehmanii Friese, 1903 da Colômbia e Peru e $X$. artifex Smith, 1874 e $X$. nogueirai Hurd \& Moure, 1960, que ocorrem no centro e sudeste do Brasil, incluindo o Estado de São Paulo). A espécie X. ruficollis Hurd \& Moure, 1963, antes pertencente ao subgênero Xylocopina Latreille, 1802, tem registro para o Perú e Amazonas (Hurd 1978, Silveira et al. 2002, Moure 2008).

\section{Notas biológicas:}

As abelhas deste subgênero constroem seus ninhos em colmos mortos e eretos de bambu sob condições naturais. Como na maioria das espécies de Xylocopa, os caracteres evidentes estão associados à cópula ou à construção dos ninhos, assim essas abelhas apresentam o dente interno apical da mandíbula amplo e truncado, aparentemente ideal para raspar um orifício de entrada e, posteriormente, as paredes internas dos colmos (Hurd 1978). Entretanto, esta modificação da mandíbula não aparece em abelhas pertencentes ao subgênero oriental Biluna Maa, cujas espécies também nidificam em colmos de bambu (Hurd \& Moure 1963). Os ninhos de Xylocopa (Biluna) tranquebarorum (Swederus, 1787) em colmos de bambu apresentam uma reentrância nas paredes internas, próxima à entrada do ninho, formada pela remoção de fragmentos utilizados para a construção dos tampões 
(Maeta et al. 1985), assim como foi observado em ninhos de $X$. frontalis em colmos de bambu (Marchi \& Melo 2010, Pereira \& Garófalo 2010). Tais reentrâncias não foram encontradas em ninhos de $X$. (Stenoxylocopa) artifex. Esta diferença etológica entre os subgêneros Stenoxylocopa e Biluna também foi apontada por Sakagami \& Laroca (1971).

\section{Xylocopa (Stenoxylocopa) artifex Smith, 1874}

\section{Diagnose:}

Fêmeas e machos foram descritos originalmente por Smith (1874) como espécies diferentes devido à diferença em sua coloração ( $X$. artifex, a fêmea e $X$. erratica, o macho). A fêmea pode ser confundida com a fêmea de $X$. (Neoxylocopa) brasilianorum, da qual é distinguida pelo tamanho, $X$. artifex é menor (14 a $16 \mathrm{~mm}$ ) que $X$. brasilianorum $(24$ a $25 \mathrm{~mm}$ ) e pela presença de pelos simples em $\mathrm{T} 1 \mathrm{em} X$. artifex e plumosos em $X$. brasilianorum. Fêmea e macho apresentam o vértice fortemente elevado acima de cada olho, distância órbito-occipital muito maior que a distância ocelo-orbital. Asas castanho-claras com brilho cúpreo. O macho apresenta o basitarso da perna posterior mais longo do que o da perna média.

\section{Distribuição:}

Região Neotropical: ARGENTINA; BRASIL (Espírito Santo, Goiás, Minas Gerais, Paraná, Rio Grande do Sul, Rio de Janeiro, Santa Catarina, São Paulo: Campos do Jordão, Cotia, Ilha de Alcatrazes, Salesópolis, Rio Claro, São Paulo) (Figura 3); PARAGUAI; URUGUAI.

\section{Notas biológicas:}

Ninhos de $X$. artifex foram encontrados em colmos mortos ou vivos de bambu e outras plantas semelhantes como Arundo donax, Bambusa, Chusquea bambusoides, Guadua e Merostachys clausseni (Hurd \& Moure 1960). Moure (1942) e Sakagami \& Laroca (1971) apresentaram informações sobre os ninhos desta espécie, como o orifício de entrada do ninho, mais longo do que largo e sempre escavado na superfície dura do entre-nó, a reutilização de cavidades antigas, entre outras. Apesar de sua distribuição se sobrepor em parte a de $X$. nogueirai, não foi observada competição por locais para nidificação entre estas espécies (Hurd 1978), mas a reutilização do ninho de uma espécie por outra foi relatada por Hurd \& Moure (1960) em que X. artifex utilizou ninhos de bambu de $X$. nogueirai. Nenhum parasita associado à espécie $X$. nogueirai foi encontrado em ninhos ou adultos de $X$. artifex (Hurd 1978).

\section{Flores visitadas:}

Tecoma stans (Bignoniaceae), Salvia melissiflora (Lamiaceae), Abutilon macranthum (Malvaceae), Tibouchina adenostenon, T. sebastianopolitana (Melastomataceae), Fuchsia regia (Onagraceae) (Schrottky 1902, Imperatriz-Fonseca et al. 2011).

\section{Atividades sazonais:}

Baseado nas datas de coletas de exemplares em museus, Hurd (1978) apresentou um padrão de atividades em que ambos os sexos foram ativos durante todo o ano na América do Sul, entretanto, foram mais abundantes nos meses de outubro a dezembro.

Datas de coleta:

No Estado de São Paulo, X. artifex foi coletada nos meses de janeiro a abril e outubro a dezembro.

\section{Xylocopa (Stenoxylocopa) nogueirai Hurd \& Moure, 1960}

\section{Diagnose:}

A fêmea de $X$. nogueirai se distingue de $X$. artifex, pois apresenta o vértice pouco elevado acima de cada olho, com a distância órbito-occipital aproximadamente igual à distância ocelo-orbital, o clípeo mais curto medianamente que a distância clípeo-ocelar e as asas castanho-escuras com brilho violáceos. O macho de $X$. nogueirai se distingue de $X$. artifex, pois apresenta o vértice menos elevado, assim como a fêmea, e o basitarso posterior aproximadamente igual em comprimento ao basitarso mediano.

\section{Distribuição:}

Região Neotropical: BRASIL (Goiás, Mato Grosso, Minas Gerais, São Paulo: Corumbataí, Cosmópolis, Pirassununga, Ribeirão Preto, São Roque) (Figura 3).

\section{Notas biológicas:}

Existe registro do parasita Physocephala testacea (Conopidae, Diptera) associado à $X$. nogueirai na Argentina, mas não há informações sobre especificidade deste parasita em relação à Xylocopa (Hurd 1978).

\section{Flores visitadas:}

Cosmos caudatus (Asteraceae), Pyrostegia venusta, Tecoma stans (Bignoniaceae), Acosmium subelegans (Fabaceae) (Camargo \& Mazucato 1984, Almeida 2002).

\section{Datas de coleta:}

No Estado de São Paulo, X. nogueirai foi coletada nos meses de maio, junho, agosto, outubro e novembro.

\section{Considerações finais}

Embora o gênero Xylocopa seja bem representado no Estado de São Paulo, existe uma grande lacuna em relação às coletas dessas abelhas nas regiões central e oeste do Estado. Além disso, nada se conhece sobre a biologia de pelo menos a metade das 22 espécies descritas.

Este trabalho fornece informações taxonômicas dos subgêneros e espécies de Xylocopa que, embora regionais, contribuem para o seu conhecimento. Do mesmo modo, as informações sobre os locais de ocorrência, as espécies de plantas visitadas e sua sazonalidade podem dar pistas para auxiliar futuros estudos com novas informações biológicas ou biogeográficas dessas abelhas.

\section{Agradecimentos}

À Fundação de Amparo à Pesquisa do Estado de São Paulo (FAPESP), pela concessão da bolsa de Pós-Doutorado à primeira autora e auxílio financeiro (Processso: 08/54100-8). Aos Drs. Carlos Roberto Brandão e Rodrigo B. Gonçalves (Museu de Zoologia, Universidade de São Paulo, MZSP) e Dra. Sílvia R. M. Pedro (Coleção Camargo, FFCLRP-USP) pelo acesso ao material consultado; à Lívia Pires do Prado pela obtenção das imagens (Laboratório de Hymenoptera, MZSP); à M. Sc. Mariana Taniguchi pela confecção das pranchas; ao M. Sc. André Luís Acosta (Laboratório de Abelhas, Universidade de São Paulo) pela confecção dos mapas; à Dra. Kelli S. Ramos (Museu de Zoologia, Universidade de São Paulo) pela revisão minuciosa do manuscrito; à Prfa. Dra. Fátima R. N. Knoll (Depto. de Ciências Biológicas, UNESP) por disponibilizar os dados sobre as espécies de Xylocopa coletadas em Bauru e na Estação Ecológica da Juréia; à Profa. Dra. Maria Cristina Gaglianone (Laboratório de Ciências Ambientais, Universidade Estadual do Norte Fluminense Darcy Ribeiro) pelo incentivo; à profa. Dra. Danúncia Urban (Depto. de Ciências Biológicas, Universidade Federal do Paraná) e ao prof. Dr. Eduardo Andrade Botelho de Almeida (FFCLRP-USP) pela atenção e sugestões. 


\section{Referências Bibliográficas}

AGOSTINI, K. \& SAZIMA, M. 2003. Plantas ornamentais e seus recursos para abelhas no campus da Universidade Estadual de Campinas, Estado de São Paulo, Brasil. Bragantia 62(3):335-343. http://dx.doi.org/10.1590/ S0006-87052003000300001

AGUILAR, J.B.V. 1998. A comunidade de abelhas (Hymenoptera: Apoidea) da Reserva Florestal de Morro Grande, Cotia, SP. Tese de doutorado, Universidade de São Paulo, São Paulo.

ALMEIDA, D. 2002. Espécies de abelhas (Hymenoptera, Apoidea) e tipificação dos méis por elas produzidos em área de cerrado do município de Pirassununga, Estado de São Paulo. Dissertação de mestrado, Escola Superior de Agricultura Luiz de Queiroz, Universidade de São Paulo, Piracicaba.

ALBUQUERQUE, L.B. 2001. Polinização e dispersão de sementes em solanáceas neotropicais.Tese de doutorado, Instituto de Biologia da Universidade Estadual de Campinas, Campinas.

ANDENA, S.E., BEGO, L.R. \& MECHI, M.R. 2005. A comunidade de abelhas (Hymenoptera, Apoidea) de uma área de cerrado (Corumbataí, $\mathrm{SP})$ e suas visitas às flores. Rev. Bras. Zoocienc. 7:55-91.

BENEVIDES, C.R., GAGLIANONE, M.C., HOFFMANN, M. 2009. Visitantes florais do maracujá-amarelo (Passiflora edulis f. flavicarpa, Passifloraceae) em areas de cultivo com diferentes proximidades a fragmentos florestais na região Norte Fluminense, RJ. Rev. Bras. Entomol. 53(3):415-421. http://dx.doi.org/10.1590/S008556262009000300016

BERNARDINO, A.S. \& GAGLIANONE, M.C. 2008. Nest distribution and nesting habits of Xylocopa ordinaria Smith (Hymenoptera, Apidae) in a restinga area in the northern Rio de Janeiro State, Brazil. Rev. Bras. Entomol. 52:434-440. http://dx.doi.org/10.1590/S008556262008000300017

BITTENCOURT JUNIOR, N.S. 2003. Auto-incompatibilidade de ação tardia e outros sistemas reprodutivos em Bignoniaceae. Tese de doutorado, Instituto de Biologia da Universidade Estadual de Campinas, Campinas.

BRITO, V.L.G., PINHEIRO, M. \& SAZIMA, M. 2010. Sophora tomentosa e Crotalaria vitellina (Fabaceae): biologia reprodutiva e interações com abelhas na restinga de Ubatuba, São Paulo. Biota Neotrop. 10(1):185-192. http://dx.doi.org/10.1590/S1676-06032010000100019

BUCHMANN, S.L. 1983. Buzz Pollination in Angiosperms. In Handbook of experimental pollination biology (B. Bentley \& T. Elias, eds.). Columbia Univ. Press, New York, p.73-113.

CAMARGO, J.M.F. \& MAZUCATO, M. 1984. Inventário da apifauna e flora apícola de Ribeirão Preto, SP, Brasil. Dusenia 14:55-87.

CAMILlO, E. 2003. Polinização do Maracujá. Ribeirão Preto, Holos.

CAMILlO, E. \& GARÓFALO, C.A. 1982. On the bionomics of Xylocopa frontalis Oliver and Xylocopa grisescens (Lepeletier) in Southern Brazil. I - Nest construction and biological cycle. Rev. Bras. Biol. 42(3):571-582.

CAMILLO, E. \& GARÓFALO, C.A. 1989. Social organization in reactivated nests of three species of Xylocopa (Hymenoptera, Anthophoridae) in southeastern Brazil. Insectes Soc. 36(2):92-105. http://dx.doi. org/10.1007/BF02225905

CAMillo, E., GARÓFAlO, C.A. \& MUCCILlO, G. 1986. On the bionomics of Xylocopa suspecta (Moure) in Southern Brazil: nest construction and biological cycle (Hymenoptera, Anthophoridae). Rev. Bras. Biol. 46(2):383-393.

CAMPOS, M.J.O. 1989. Estudo das interações entre a comunidade de Apoidea, na procura de recursos alimentares e a vegetação de cerrado na reserva de Corumbataí-SP. Tese de doutorado, Universidade Federal de São Carlos, São Carlos.

COCKERELL, T.D.A. 1912. Descriptions and records of bees - XLVII. Ann. Mag. Nat. Hist. Series 8(10):484-494.

CORBET, S.A. \& WILLMER, P.G. 1980. Pollination of the yellow passion fruit: Nectar, pollen and carpenter bees. J. Agr. Sci. 95:655-666. http:// dx.doi.org/10.1017/S0021859600088055
DEL LAMA, M.A. \& PERUQUETI, R.C. 2006. Mortalidade de abelhas visitantes de flores de Caesalpinia peltophoroides Benth (Leguminosae) no Estado de São Paulo, Brasil. Rev. Bras. Entomol. 50(4):547-549. http:// dx.doi.org/10.1590/S0085-56262006000400017

DUTRA, J.C.S. \& MACHADO, V.L.L. 2001. Entomofauna visitante de Stenolobium stans (Juss.) Seem (Bignoniaceae), durante seu período de floração. Neotrop. Entomol. 30(1):43-53. http://dx.doi.org/10.1590/ S1519-566X2001000100008

ENDERLEIN, G. 1913. Zur Kenntnis der Xylocopen Südamerikas und übereinen Zwitter von Xylocopa ordinaria. Arch. Naturgeschichte (A) 79:156-170.

ESRI, 2006. ArcMap 9.2. Environmental Systems Research Institute, Inc.

FORNI-MARTINS, E.R., MARQUES, M.C.M. \& LEMES, M.R. 1998. Biologia floral e reprodução de Solanum paniculatum L. (Solanaceae) no Estado de São Paulo, Brasil. Rev. Bras. Bot. 21(2):117-124. http:// dx.doi.org/10.1590/S0100-84041998000200002

FRANCO, A.L.M. 1995. Pollination ecology and breeding systems of seven species of Phaseoleae (Fabaceae). Tese de doutorado, Universidade Estadual de Campinas, Campinas

FREITAS, B.M. \& OLIVEIRA FILHO, J.H. 2001. Criação racional de mamangavas para polinização em áreas agrícolas. Banco do Nordeste, Fortaleza.

GERLING, D., VELTHUIS, W.H.D. \& HEFETZ, A. 1989. Bionomics of the large carpenter bee of the genus Xylocopa. Annu. Rev. Entomol. 34:163190. http://dx.doi.org/10.1146/annurev.en.34.010189.001115

GIMENES, M., FIGUEIREDO, N.A. \& SANTOS, A.H.P. 2006 Atividades relacionadas à construção e aprovisionamento de ninhos de Xylocopa subcyanea (Hymenoptera, Apidae) em uma área de restinga na Bahia, Brasil. Iheringia, Ser. Zool. 96(3):299-304. http://dx.doi.org/10.1590/ S0073-47212006000300005

GONÇALVES, R.B. \& BRANDÃO, C.R.F. 2008. Diversidade de abelhas (Hymenoptera, Apidae) ao longo de um gradiente latitudinal na Mata Atlântica. Biota Neotrop. 8:51-61. http://dx.doi.org/10.1590/S167606032008000400004

GOTTSBERGER, G. \& SILBERBAUER-GOTTSBERGER, I. 1988. Evolution of flower structures and pollination in Neotropical Cassiinae (Caesalpiniaceae) species. Phyton 28:293-320.

HOFFMANN, M. 1995. Abelhas nativas (Hymenoptera, Apoidea) numa área agrícola no Sul do Brasil e sua importância para a polinização de Phaseolus vulgaris (Leguminosae). Iheringia, Ser. Zool. 129-133.

HOFFMANN, M., PEREIRA, T.N.S., MERCADANTE, M.B. \& GOMES, A.R. 2000. Polinização de Passiflora edulis f. flavicarpa (Passiflorales, Passifloraceae) por abelhas (Hymenoptera, Anthophoridae) em Campos dos Goytacazes, Rio de Janeiro. Iheringia, Ser. Zool. 89:149-152.

HURD, P.D., Jr. 1978. An Annotated Catalog of the Carpenter Bees (Genus Xylocopa Latreille) of the Western Hemisphere (Hymenoptera: Anthophoridae). Smithsonian Institution Press, Washington. 106p.

HURD, P.D., Jr. \& MOURE, J.S. 1960. A New World subgenus of bamboonesting carpenter bees belonging to the genus Xylocopa Latreille (Hymenoptera: Apoidea). Ann. Entomol. Soc. Am. 63:809-821.

HURD, P.D., Jr. \& MOURE, J.S. 1961. Systematics of the carpenter bee types (genus Xylocopa Latreille) contained in the collections of the Museo Argentino de Ciencias Naturales "Bernardino Rivadavia," Buenos Aires (Hymenoptera: Apoidea). J. Kans. Entomol. Soc. 34:181-195.

HURD, P.D., Jr \& MOURE, J.S. 1963. A classification of the large carpenter bees (Xylocopini) (Hymenoptera, Apoidea). Univ. Calif. Publ. Entomol. 29:1-365.

IMPERATRIZ-FONSECA, V.L., ALVES-DOS-SANTOS, I., SANTOSFILHO, P.S., ENGELS, W., RAMALHO, M., WILMS, W., AGUILAR, J.B.V., PINHEIRO-MACHADO, C.A., ALVES, D.A. \& KLEINERT, A.M.P. Checklist das Abelhas e Plantas melitófilas no Estado de São Paulo, Brasil. Biota Neotrop. 11(1a): http://www.biotaneotropica.org. $\mathrm{br} / \mathrm{v} 11 \mathrm{n} 1 \mathrm{a} / \mathrm{pt} / \mathrm{abstract}$ inventory+bn0321101a2011 (último acesso em 10/02/2011). 
KOSCHNITZKE, C. \& SAZIMA, M. 1997. Biologia floral de cinco espécies de Passiflora L. (Passifloraceae) em mata semidecídua. Rev. Bras. Bot. 20: 19-126. http://dx.doi.org/10.1590/S0100-84041997000200002

LUCIA, M., ABRAHAMOVICH, A.H. \& ALVAREZ, L.J. 2009. A gynandromorph of Xylocopa nigrocincta Smith (Hymenoptera: Apidae). Neotrop. Entomol. 38(1):155-157. http://dx.doi.org/10.1590/S1519566X2009000100020

MAETA, Y., SAKAGAMI, S.F. \& SHIOKAWA, M. 1985. Observations on a nest aggregation of the Taiwanese bamboo carpenter bee Xylocopa (Biluna) tranquebarorum tranquebarorum (Hymenoptera, Anthophoridae). J. Kans. Entomol. Soc. 58 (1):36-41.

MAILD, F. 1912. Die Xylocopen (Holzbienen) des Wiener Hofmuseums: Ein Beitrag zu einer Monographie dieser Gattung. Ann. K. K. Naturh. Hofsmus. Wien 26: 249-330.

MALERBO-SOUZA, D.T., NOGUEIRA-COUTO, R.H. \& TOLEDO, V.A.A. 2002. Insetos associados às flores de diferentes espécies de maracujá (Passiflora spp.). Acta Sci. 24(5):1269-1274.

MANENTE-BAESTIERI, F.C.D.L \& MACHADO, V.L.L. 1999. Entomofauna visitante das flores de Cassia spectabilis (L.) DC. (Leguminosae). Ann. Soc. Entomol. Bras. 28(3):429-437. http://dx.doi.org/10.1590/S030180591999000300007

MARCHI, P \& MELO, G.A.R. 2010. Biologia de nidificação de Xylocopa (Neoxylocopa) frontalis (Olivier) (Hymenoptera, Apidae, Xylocopini) em Morretes, Paraná. Oecologia 14(1):210-231. http://dx.doi.org/10.4257/ oeco.2010.1401.12

MATEUS, S. 1998. Abundância relativa, fenologia e visita às flores pelos Apoidea do cerrado da Estação Ecológica de Jataí - Luiz Antônio - SP. Dissertação de mestrado, Faculdade de Filosofia, Ciências e Letras de Ribeirão Preto, Universidade de São Paulo, Ribeirão Preto.

MELO, G.A.R., VARASSIN, I.G., VIEIRA, A.O.S., MENESES, J.R., LÖWENBERG-NETO, P., BRESSAN, D.F., ELBL, P.M., OLIVEIRA, P.C., ZANON, M.M.F., ANDROCIOLI, H.G., XIMENES, B.M.S., ALVES, D.S.M., CERVIGNE, N.S., PRADO, J. \& IDE, A.K. 2005. Polinizadores de maracujás do Paraná. Subprojeto 02.02.89. Relatório Técnico. Probio Edital 02/2003. Uso sustentável e restauração da diversidade de polinizadores autócones na agricultura e nos ecossistemas associados. MMA/CNPq/GEF/BIRD, Curitiba.

MICHENER, C.D. 1954. Bees of Panamá. Bull. Am. Mus. Nat. Hist. 104:1-176.

MICHENER, C.D. 2007. The bees of the world. The Johns Hopkins University Press. Baltimore, London.

MINCKLEY, R.L. 1998. A cladistic analysis and classification of the subgenera and genera of the large carpenter bees, tribe Xylocopini (Hymenoptera: Apidae). Sci. Pap. Nat. Hist. Mus. Univ. Kans. 9:1-47.

MONTALVA, J., DUDLEY, L.S. \& ARROYO, M.T.K. 2008. First record of Xylocopa (Schonnherria) splendidula Lepeletier 1841 (Hymenoptera: Apidae: Xylocopini) in the Mediterranean zone of Chile. Gayana (Concepc.) 72(2) http://www.scielo.cl/scielo.php?script=sci_ arttext\&pid=S0717-65382008000200012\&lng=en\&nrm=iso (último acesso em 23/02/2011).

MOURE, J.S. 1942. Abelhas de Salobra (Hym. Apoidea). Pap. Av. II(21):291-321.

MOURE, J.S. 1949. Notas sôbre algunas abejas de Tacanas, Tucumán. Argentina, II (Hymenopt. Apoidea). Rev. Entomol. 20:437-460.

MOURE, J.S. 2008. Xylocopini Latreille, 1802. In Catalogue of Bees (Hymenoptera, Apoidea) in the Neotropical Region (J. S. Moure, D. Urban \& G. A. R. Melo, orgs.). http://www.moure.cria.org.br/catalogue (último acesso em 26/06/2011).

MOURE, J.S. \& CAMARGO, J.M.F. 1988. Uma nova espécie de Xylocopa (Neoxylocopa) do Brasil (Hymenoptera, Apoidea). Rev. Bras. Entomol. 32(2):219-214.

NASCIMENTO, E.A. \& DEL-CLARO, K. 2007. Floral visitors of Chamaecrista debilis (Vogel) Irwin \& Barneby (Fabaceae - Caesalpinioideae) at cerrado of Estação Ecológica de Jataí, São Paulo State, Brazil. Neotrop. Entomol. 36(4):619-624. PMid:17934632. http://dx.doi.org/10.1590/ S1519-566X2007000400024
NISHIDA, T. 1963. Ecology of the pollinators of passion fruit. Honolulu. Tech. Bull. 55, University of Hawaii, Honolulu.

OLIVEIRA FILHO, J.H. \& FREITAS, B.M. 2003. Colonização e biologia reprodutiva de mamangavas (Xylocopa frontalis) em um modelo de ninho racional. Cienc. Rural 33(4):693-697. http://dx.doi.org/10.1590/ S0103-84782003000400017

PEDRO, S.R.M. \& CAMARGO, J.M.F. 1999. Hymenoptera, Apiformes. In Biodiversidade do Estado de São Paulo, Brasil, 5: Invertebrados terrestres (C.R.F. Brandão \& E. M. Cancello, eds.). FAPESP, São Paulo, p.193-211.

PEDRO, S.R.M. 1992. Sobre as abelhas (Hymenoptera, Apoidea) em um ecossistema de cerrado (Cajuru, NE do estado de São Paulo): composição, fenologia e visita às flores. Dissertação de mestrado. Faculdade de Filosofia, Ciências e Letras de Ribeirão Preto, Universidade de São Paulo. Ribeirão Preto.

PEREIRA, M. 2002. Biologia de nidificação de Xylocopa frontalis e Xylocopa grisescens (Hymenoptera, Apidae, Xylocopini) em ninhos-armadilha. Tese de doutorado, Faculdade de Filosofia, Ciências e Letras de Ribeirão Preto, Universidade de São Paulo. Ribeirão Preto.

PEREIRA, M. \& GARÓFALO, C.A. 2010. Biologia da nidificação de Xylocopa frontalis e Xylocopa grisescens (Hymenoptera, Apidae, Xylocopini) em ninhos-armadilha. Oecologia 14(1):193-209. http:// dx.doi.org/10.4257/oeco.2010.1401.11

PINHEIRO-MACHADO, C.A. 2002. Diversidade e conservação de Apoidea. Tese de doutorado, Universidade de São Paulo, São Paulo.

PINHEIRO, M. \& SAZIMA, M. 2007. Visitantes florais e polinizadores de seis espécies arbóreas de Leguminosae melitófilas na Mata Atlântica no Sudeste do Brasil. Rev. Bras. Bioc. 5(1):447-449.

RAMALHO, M.1995. A diversidade de abelhas (Apoidea-Hymenoptera) em um remanescente de Floresta Atlântica, em São Paulo. Tese de doutorado, Universidade de São Paulo, São Paulo.

RAMAlho, M., BATISTA, M.A. \& SILVA, M. 2004. Xylocopa (Monoxylocopa) abbreviata Hurd \& Moure (Hymenoptera: Apidae) e Encholirium spectabile (Bromeliaceae): uma associação estreita no semi-árido do Brasil tropical. Neotrop. Entomol. 33(4):417-425. http:// dx.doi.org/10.1590/S1519-566X2004000400004

RUGGIERO, C.; LAM-SANCHEZ, A. \& BANZATTO, D.A. 1976. Studies on natural and controlled pollination in yellow passion fruit (Passiflora edulis flavicarpa Deg.). Acta hort. 57:121-124.

SAGE, R.D. 1968. Observations on feeding, nesting, and territorial behavior of carpenter bees genus Xylocopa in Costa Rica. Ann. Entomol. Soc. Am. 61(4):884-889.

SAKAGAMI, S.F. \& LAROCA, S. 1971. Observations on the bionomics of some Neotropical Xylocopini bees, with some comparative biofaunistiv notes (Hymenoptera, Anthophoridae). J. Fac. Sci. Hokkaido U. 18:57-127.

SAZIMA, I. \& SAZIMA, M. 1989 Mamangavas e irapuás (Hymenoptera, Apoidea): visitas, interações e consequências para a polinização do marcujá (Passifloraceae). Rev. Bras. Entomol. 33(1):109-118.

SCHLINDWEIN, C., SCHLUMPBERGER, B., WITTMANN, D. \& MOURE, J.S. 2003. O gênero Xylocopa Latreille no Rio Grande do Sul, Brasil (Hymenoptera, Anthophoridae). Rev. Bras. Entomol. 47(1):107-118. http://dx.doi.org/10.1590/S0085-56262003000100016

SCHLUMPBERGER, B.O. \& WITTMANN, D. 2000. New odour glands in Xylocopa males (Hymenoptera: Apoidea: Anthophoridae). J. Hymenopt. Res. 9(2):363-369.

SCHROTTKY, C. 1902. Ensaio sobre as abelhas solitárias do Brasil. Rev. Mus. Paulista 5:330-613.

SILVA, C.I., BALLESTEROS, P.L.O., PALMERO, M.A., BAUERMANN, S.A., EVALDIT, A.C.P. \& OLIVEIRA, P.E. 2010. Catálogo polínico - Palinologia aplicada em estudos de conservação de abelhas do gênero Xylocopa no Triângulo Mineiro. Editora da Universidade Federal de Uberlândia, Uberlândia.

SILVEIRA, F.A. 2002. The bamboo-nesting carpenter bee, Xylocopa (Stenoxylocopa) artifex Smith (Hymenoptera: Apidae), also nesting fibrous branches of Vellozia (Velloziaceae). Lundiana 3(1):57-60. 
SILVEIRA, F.A.; MELO, G.A.R. \& ALMEIDA, E.A.B. 2002. Abelhas brasileiras. Sistemática e identificação. Composição \& Arte, Belo Horizonte.

SMITH, F. 1853. Catalogue of hymenopterous insects in the collection of the British Museum. Part I. Andrenidae and Apidae. British Museum (Natural History), London.

SMITH, F. 1874. Monograph of the genus Xylocopa Latr. Trans. Entomol. Soc. London 247-302.

TELLERÍA, M.C. 1999. Pollen collected by Xylocopa augusti (Hymenoptera, Apidae) in the northwestern of the Buenos Aires province, Argentina. Darwiniana 37(3-4):253-258.

VARASSIN, I.G. \& SILVA, A.G. 1999. A melitofilia em Passiflora alata Dryander (Passifloraceae), em vegetação de restinga. Rodriguesia 50:517.

VELTHUIS, H.H.W. \& CAMARGO, J.M.F. 1975a. Observations on Male Territories in a Carpenter Bee, Xylocopa (Neoxylocopa) hirsutissima Maidl (Hymenoptera, Anthophoridae). Zeitsch. Tierpsychol. 38:409-418. http://dx.doi.org/10.1111/j.1439-0310.1975.tb02013.x
VELTHUIS, H.H.W. \& CAMARGO, J.M.F. 1975b. Further observations on the function of male territories in the carpenter bee, Xylocopa (Neoxylocopa) hirsutissima Maidl (Hymenoptera: Anthophoridae). Neth. J. Zool. 25:516-528. http://dx.doi.org/10.1163/002829675X00092

VIANA, B.F., KLEINERT, A.M.P. \& SILVA, F.O. 2002. Ecology of Xylocopa (Neoxylocopa) cearensis (Hymenoptera, Anthophoridae) in Abaeté sand dunes, Salvador, Bahia. Iheringia, Ser. Zool. 92(4):47-57.

VITALI-VEIGA, M.J., DUTRA, J.C.S. \& MACHADO, V.L.L. 1999 Visitantes florais de Lagerstroemia speciosa Pers: (Lythraceae). Rev. Bras. Zool. 16(2):397-407. http://dx.doi.org/10.1590/S010181751999000200006

WILMS, W. 1995. Die Bienenfauna im Küstenregenwald Brasiliens und ihre Beziehungen zu Blütenpflanzen: Fallstudie Boracéia, São Paulo. Tese de doutorado, Eberhard-Karls-Universität Tübingen, Tübingen, Alemanha.

WITTMANN, D. \& SCHOLZ, E. 1989. Nectar dehydration by male carpenter bees as preparation for mating flights. Behav. Ecol. Sociob. 25:387-391. http://dx.doi.org/10.1007/BF00300184

Recebido em 21/09/2011 Versão reformulada recebida em 08/02/2013 Publicado em 17/04/2013 


\section{Chave para os subgêneros de Xylocopa presentes no Estado de São Paulo:}

\section{Fêmeas:}

Modificada de Minckley 1998.

1- Carena longitudinal mediana fortemente elevada e contínua em todos os esternos (Figura 5 A); clípeo emoldurado por crista contínua (Figura $5 \mathrm{~b} ; 7 \mathrm{e}, \mathrm{h}$ ).

- Carena longitudinal mediana ausente ou parcialmente elevada em alguns esternos; clípeo sem crista ou emoldurado por crista descontínua (Figura 4.

2(1)- Dente superior da mandíbula tão largo quanto ou mais estreito que o inferior; margem dorsolateral do clípeo elevada em relação á área parocular adjacente (Figura 5b); margem de S1 inteira (reta); disco de T1 glabro ou com pelos plumosos.

Neoxylocopa

- Dente superior da mandíbula mais largo que o inferior; margem dorsolateral do clípeo não elevada em relação á área parocular (Figura 7e, h); margem de S1 encurvada medianamente; disco de T1 com pelos simples.

Stenoxylocopa

3(1)- Ápice distal do escapo ultrapassa o nível superior dos olhos; comprimento do flagelo excede o do olho; clípeo mais longo que a metade da sua largura; comprimento mediano do clípeo tão longo quanto a distância entre o clípeo e o ocelo anterior (Figura 5a); grádulo presente em T3 e T4; integumento fracamente metálico (Figura 5b, c).

Dasyxylocopa

- Ápice distal do escapo não ultrapassa ou ultrapassa pouco o nível da margem acima do olho; comprimento do flagelo aproximadamente igual ao do olho; clípeo mais curto que metade da sua largura; comprimento mediano do clípeo mais curto que a distância entre o clípeo e o ocelo anterior; grádulo ausente em T3 e T4; integumento quase sempre com brilho metálico (Figura 6a, b, f, k, 1) .....

Schonnherria

\section{Machos:}

Modificada de Minckley 1998.

1- Integumento predominantemente ferrugíneo ou amarelado; tégula ferrugínea; pilosidade ferrugínea ou amarelada .

- Integumento predominantemente preto; tégula preta; pilosidade enegrecida a, às vezes em parte esbranquiçada ou amarelada .................. 2

2(1)- Integumento sem brilho metálico; escapo preto sem lista amarela frontal; clípeo com mancha amarelada apenas nas laterais (Figura 7a, d)

Stenoxylocopa

- Integumento geralmente com brilho metálico; escapo preto com lista amarela frontal; clípeo com mancha amarelada na parte mediana e nas laterais ou totalmente amarelado (Figura 4f, 6c, d, e, i, m, n).

Dasyxylocopa

3(2)- Clípeo com mancha amarelada na parte mediana e nas laterais (Figura 4f); grádulo presente em T1 e de T3 a T5

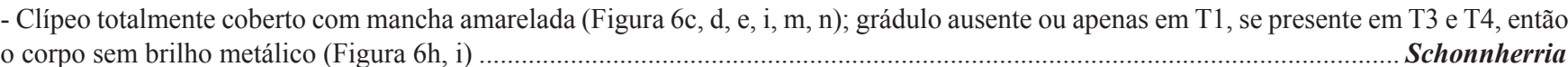

\section{Chave para as espécies do subgênero Neoxylocopa do Estado de São Paulo:}

\section{Fêmeas:}

\section{Modificada de Schrottky 1902.}

(Os machos da maioria das espécies não foram examinados, pois não foi possível associar os sexos das espécies deste subgênero).

1- Abelhas grandes, comprimento do corpo em torno de 30 a 36 m; sem carena ou tubérculo frontal (entre as antenas); com proeminências acima de cada ocelo posterior; laterais do clípeo fortemente protuberantes (Figura 5b); às vezes com os três ou quatro primeiros tergos com faixas ferrugíneas

X. frontalis (Olivier)

- Abelhas não maiores que $30 \mathrm{~mm}$; com carena ou tubérculo frontal (entre as antenas); sem proeminências acima dos ocelos posteriores; margens laterais do clípeo não proeminentes

2- Integumento predominantemente preto, os três ou quatro primeiros tergos com faixas ferrugíneas (Figura 5c) .........X. nigrocincta Smith

- Integumento completamente preto

3- Abelhas grandes, comprimento do corpo em torno de 27 a $30 \mathrm{~mm}$; pilosidade dorsal em parte esbranquiçada ou ferrugínea (Figura $5 \mathrm{~d}$, e) .. 4

- Abelhas com comprimento em torno de 20 a $26 \mathrm{~mm}$; pilosidade completamente preta.

4- Cabeça e mesossoma com pilosidade preta; metassoma com pelos ferrugíneos a partir das laterais de T2 (Figura 5e)....X. augusti Lepeletier - Vértice com pelos brancos; mesossoma com pilosidade esbranquiçada; metassoma com pelos pretos (Figura 5d)......X. grisescens Lepeletier 5- Metassoma praticamente glabro, $\mathrm{T} 1 \mathrm{com}$ poucos pontos no disco e alguns pelos plumosos apenas no bordo anterior (Figura $5 \mathrm{f}$ ) ............X. rotundiceps Smith

- T1 densamente coberto com pelos plumosos

6- Asas castanho-claras, quase transparentes, com brilho cúpreo-purpúreo; metassoma com pelos finos e longos, mais esparsos no disco dos tergos (Figura 5g). X. brasilianorum (Linnaeus)

- Asas castanho-escuras, com brilho violáceo ou esverdeado; pelos curtos em T2, se longos, cerdosos e uniformes em todo o metassoma (Figura 5h, I) 

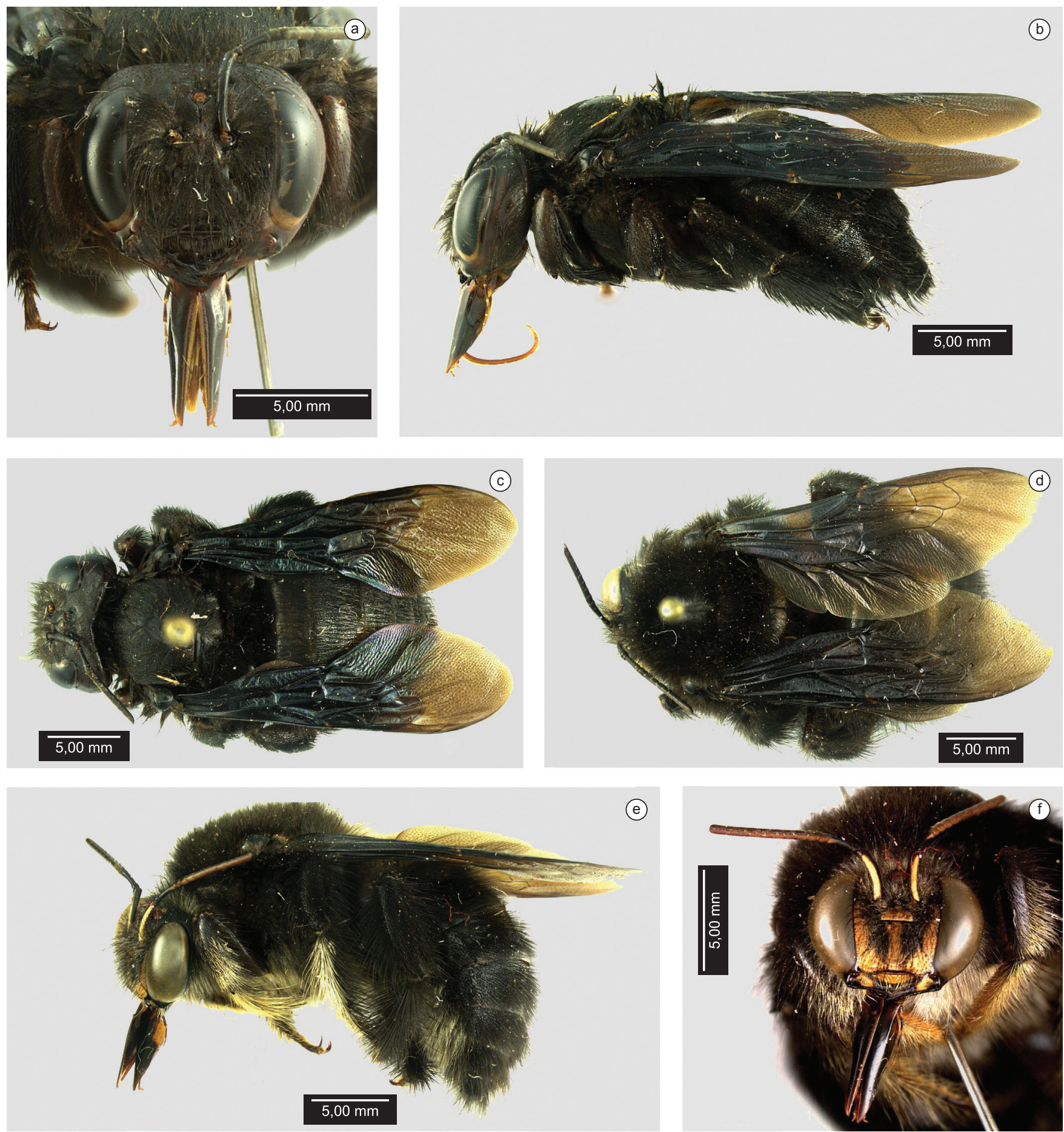

Figura 4. X. (Dasyxylocopa): (a, b, c) X. bimaculata (fêmea) vista frontal, lateral, dorsal; (d, e, f) X. bimaculata (macho) vista dorsal, lateral, frontal. Escala $=5,00 \mathrm{~mm}$.

Figure 4. X. (Dasyxylocopa): (a, b, c) X. bimaculata (female) front, lateral and dorsal view; (d, e, f) X. bimaculata (male) dorsal, lateral and frontal view. Scale $=5.00 \mathrm{~mm}$.

7- Metassoma inteiramente cerdoso, com pelos longos e densos em todos os tergos (Figura 5h)...... X. hisurtissima Maidl

- Disco de T2 e T3 com pilosidade curta, mais longa e densa nas laterais dos tergos (Figura 5i)..... 8

8- Asas com forte brilho violáceo; região mediana do disco de T2 com pontuação densa; distância entre os pontos na igual ou menor que seu diâmetro; pelos sobrepassando o bordo dos pontos, contrastando com a margem lisa dos tergos (Figura 5i)..... X. ordinaria Smith

- Asas com forte brilho verde metálico, ás vezes com brilho violáceo próximo á base; região mediana do disco de T2 com pontuação moderadamente esparsa a esparsa; distância entre os pontos na maior que seu diâmetro; pelos curtíssimos no disco, mais densos nas laterais

X. suspecta Moure \& Camargo 

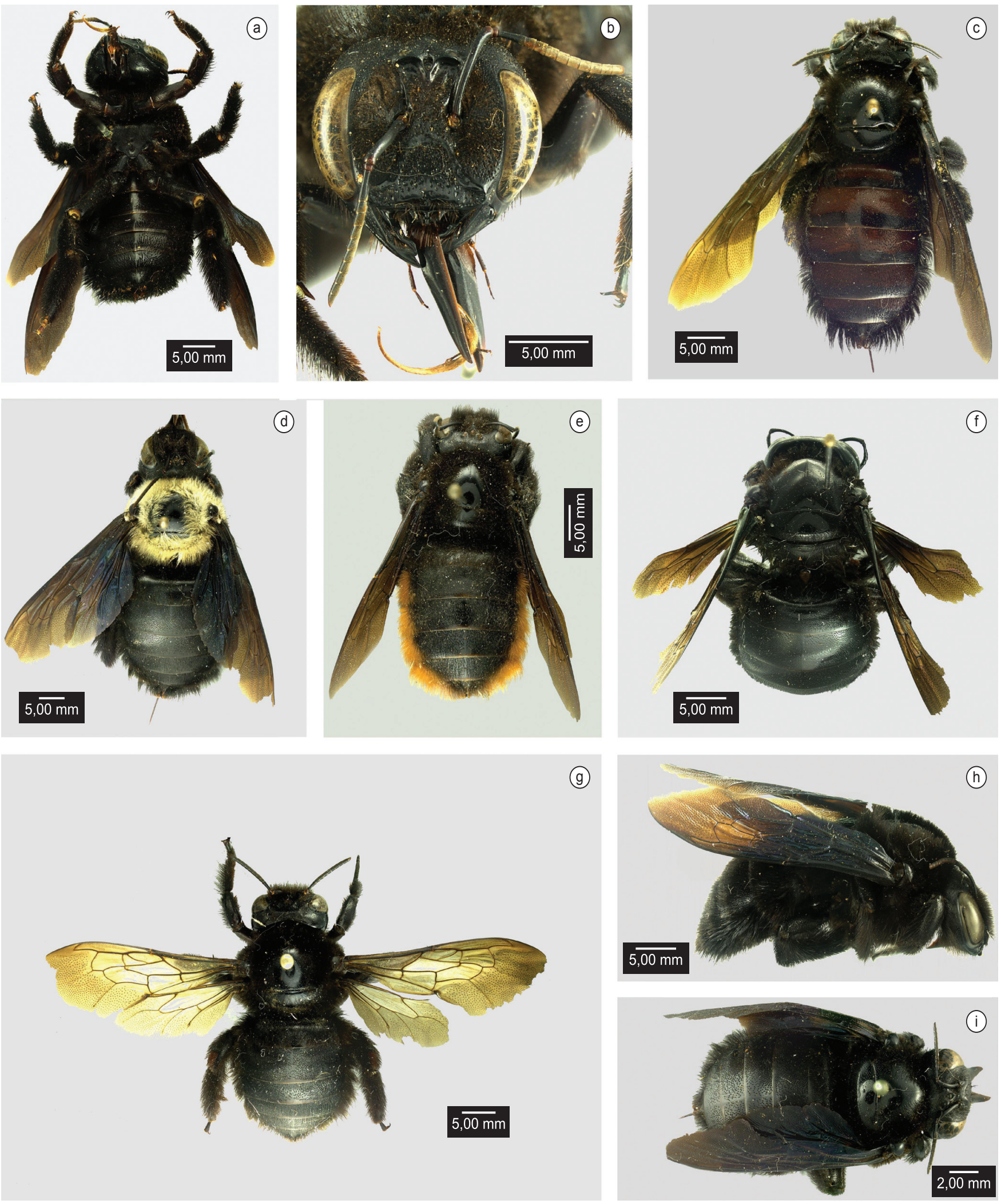

Figura 5. X. (Neoxylocopa): (a) X. frontalis (fêmea) vista ventral; (b) X. frontalis (fêmea) vista frontal; (c) X. nigrocincta (fêmea) vista dorsal; (d) X. grisescens (fêmea) vista dorsal; (e) X. augusti (fêmea) vista dorsal; (f) X. rotundiceps (fêmea) vista dorsal; (g) X. brasilianorum (fêmea) vista dorsal; (h) X. hirsutissima (fêmea) vista lateral; (i) $X$. ordinaria (fêmea) vista dorsal. Escala $=5,00 \mathrm{~mm}$, exceto para figura $\mathrm{I}=2,00 \mathrm{~mm}$.

Figure 5. X. (Neoxylocopa): (a) X. frontalis (female) ventral view; (b) X. frontalis (female) front view; (c) X. nigrocincta (female) dorsal view; (d) X. grisescens (female) dorsal view; (e) X. augusti (female) dorsal view; (f) X. rotundiceps (female) dorsal view; (g) X. brasilianorum (female) dorsal view; (h) X. hirsutissima (female) lateral view; (i) X. ordinária (female) dorsal view. Scale $=5.00 \mathrm{~mm}$, except for figure $\mathrm{I}=2.00 \mathrm{~mm}$. 


\section{Chave para as espécies do subgênero Schonnherria do Estado de São Paulo:}

\section{Fêmeas:}

Modificada de Moure 1949.

(As fêmeas de X. chrysopoda não são conhecidas).

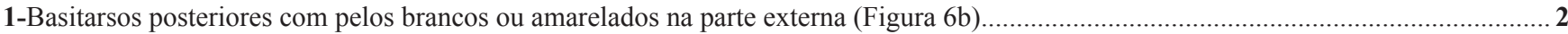

- Basitarsos posteriores com pelos pretos na parte externa (Figura 6k)

2(1)- Integumento preto, tergos com faixas largas de cerdas amareladas, interrompidas ao meio (Figura 6b) ...................... pulchra Smith

- Integumento esverdeado (principalmente no metassoma, pernas médias e posteriores); tergos sem faixas de cerdas ou muito estreitas e reduzidas às extremidades laterais

3(2)- Cabeça, principalmente a face e genas com pelos esbranquiçados (Figura 6k) X. muscaria (Fabricius)

Cabeça apenas com pelos pretos

4(3)- Abelhas menores, em torno de $14 \mathrm{~mm}$; laterais de E3 e E4 com pelos brancos.

- Abelhas maiores, em torno de $20 \mathrm{~mm}$; laterais de E3 e E4 sem pelos brancos.

5(4)- Genas com pontos esparsos e poucos pelos pretos; disco do metassoma praticamente glabro (Figura 61).

X. macrops Lepeletier

- Genas com pontos densos, cobertas com pelos pretos; cerdas visíveis no disco do metassoma.

6(5)- Integumento predominantemente preto, azul esverdeado escuro no metassoma

Integumento azul intenso em todo o corpo (Figura 6a)

7(4)- Integumento preto, tergos com faixas integumentares acastanhadas.

X.................... 6

Integumento preto, parte posterior do mesossoma e metassoma esverdeado.

X. splendidula Lepeletier

X. simillima Smith

Machos:

(Os machos de $X$. simillima não são conhecidos, os machos de $X$. pulchra não foram examinados).

1- Olhos grandes e muito convergentes superiormente, quase se tocando no vértice (distância superior entre as órbitas aproximadamente igual ao diâmetro do ocelo) (Figura 6c, e)

X. dimidiata Latreille

- Olhos mais afastados no vértice (distância superior entre as órbitas maior que o diâmetro do ocelo) (Figura 6d, i, m, n)

X. macrops Lepeletier

2(1)- T1 com pilosidade esbranquiçada ou amarelada (Figura 6c).

.

- T1 com pilosidade preta.

X. dimidiata Latreille

3(1)- Pilosidade predominantemente preta na cabeça; laterais de T2 a T4 com pilosidade amarelada.

- Pilosidade esbranquiçada nas genas e parte ventral do metassoma; T5 com pelos brancos e pretos e T6 com pelos brancos e densos

4(1)- Basitarsos posteriores com pelos esbranquiçados ou amarelados (Figura 6h)

5

Basitarsos posteriores com pelos pretos (Figura 6j)

6

5(4)- Integumento com brilho esverdeado; olhos levemente convergentes superiormente; mancha amarelada do clípeo até os ocelos posteriores (Figura 6n); margem posterior de T2 a T5com pilosidade esbranquiçada; ápice do metassoma com pelos pretos X. varians Smith Integumento preto, levemente metálico; olhos fortemente convergentes superiormente; mancha amarelada do clípeo até os alvéolos antenais (Figura 6i); margem posterior de T2 a T6 com pilosidade preta; ápice do metassoma com pelos amarelados (Figura 6h) ........X. chrysopoda Schrottky

6(4)- Integumento azul esverdeado escuro no metassoma (Figura 6m)

X. subcyanea Pérez

Integumento predominantemente azul (Figura 6d, j). X. splendidula Lepeletier

\section{Chave para as espécies do subgênero Stenoxylocopa do Estado de São Paulo:}

\section{Fêmeas e machos:}

Modificada de Hurd 1978.

1- Machos (face com manchas amarelas) (Figura 7a, d) . 2 Fêmeas (face totalmente preta, sem manchas) (Figura 7e, h) 3 2(1)- Vértice fortemente elevado acima de cada olho; distância órbito-occipital muito maior que a distância ocelo-orbital; basitarso da perna posterior mais longo do que o da perna média (Figura 7a, b, c).

$X$. artifex Smith

- Vértice pouco elevado acima de cada olho; distância órbito-occipital aproximadamente igual à distância ocelo-orbital; basitarso da perna posterior aproximadamente igual em comprimento ao da perna média (Figura $7 \mathrm{~d}$ )

X. nogueirai Hurd \& Moure

3(1)- Vértice fortemente elevado acima de cada olho; distância órbito-occipital muito maior que a distância ocelo-orbital; clípeo mais longo medianamente que a distância clípeo-ocelar (Figura 7e); asas castanho-claras com brilho cúpreo (Figura 7f, g)......

X. artifex Smith

- Vértice pouco elevado acima de cada olho; distância órbito-occipital aproximadamente igual à distância ocelo-orbital; clípeo mais curto medianamente que a distância clípeo-ocelar (Figura 7h); asas castanho-escuras com brilho violáceo (Figura 7i) .....X. nogueirai Hurd \& Moure 

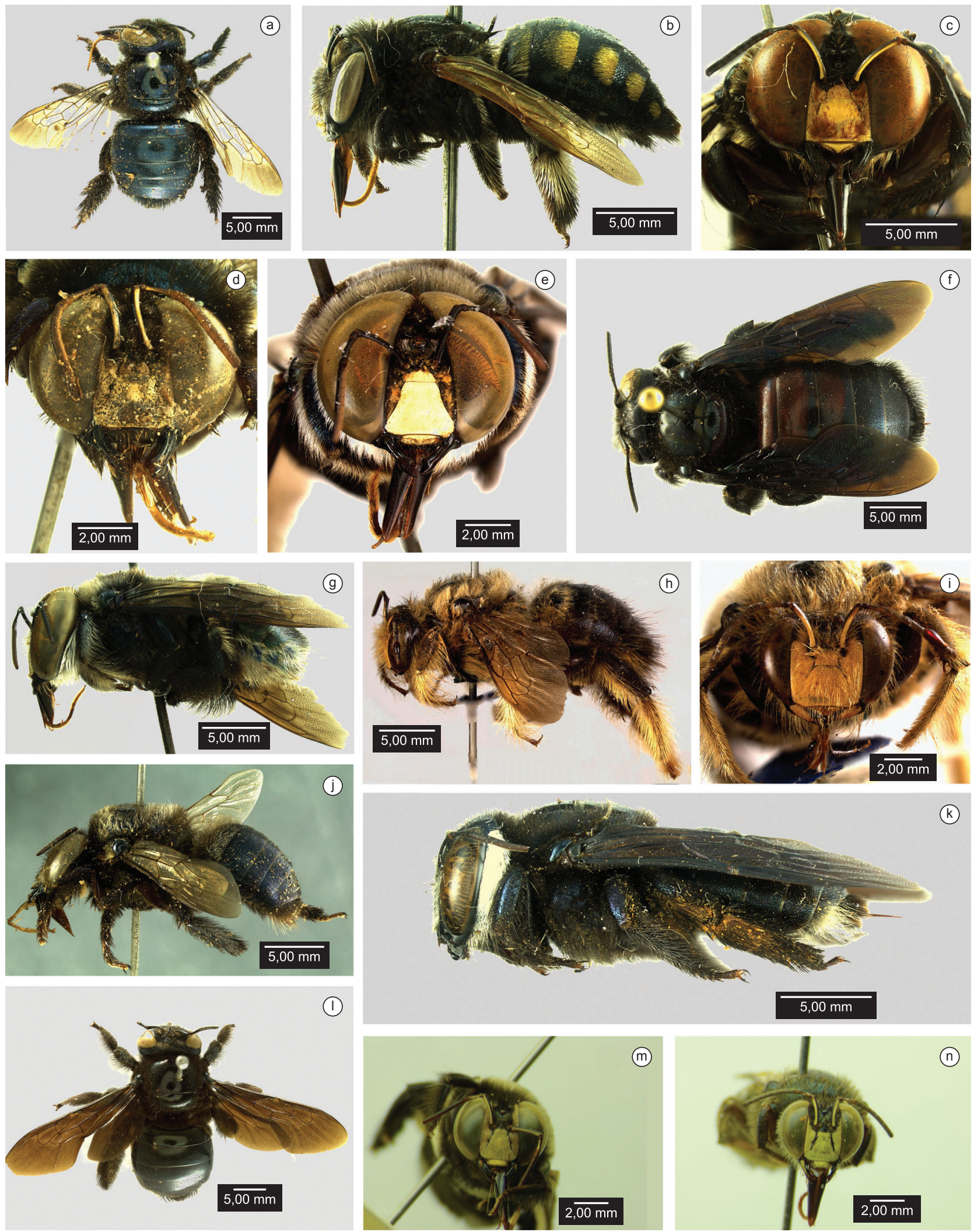

(n)

Figura 6. X. (Schonnherria): (a) X. splendidula (fêmea) vista dorsal; (b) X. pulchra (fêmea) vista lateral; (c) X. macrops (macho) vista frontal; (d) X. splendidula (macho) vista frontal; (e) X. muscaria (macho) vista frontal; (f) X. simillima (fêmea) vista dorsal; (g) X. muscaria (macho) vista lateral; (h, i) X. chrysopoda (macho) vista lateral, frontal; (j) X. splendidula (macho) vista lateral; (k)X. muscaria (fềmea) vista lateral; (1)X. macrops (fêmea) vista dorsal; (m) X. subcyanea (macho) vista frontal; (n) X. varians (macho) vista frontal. Escala para figuras a, b, c, f, g, h, j, k, l= 5,00 mm, figuras d, e, i, m, n =2,00 mm.

Figure 6. X. (Schonnherria): (a) X. splendidula (female) dorsal view; (b) X. pulchra (female) lateral view; (c) X. macrops (male) frontal view; (d) X. splendidula (male) frontal view; (e) X. muscaria (male) frontal view; (f) X. simillima (female) dorsal view; (g) X. muscaria (male) lateral view; (h, i) X. chrysopoda (male) lateral and front view; (j) X. splendidula (male) lateral view; (k) X. muscaria (female) lateral view; (l) X. macrops (female) dorsal view; (m) X. subcyanea (male) frontal view; (n) X. varians (male) frontal view. Scale for figures a, b, c, f, g, h, j, k, l=5.00 mm, figures d, e, i, m, $\mathrm{n}=2.00 \mathrm{~mm}$. 

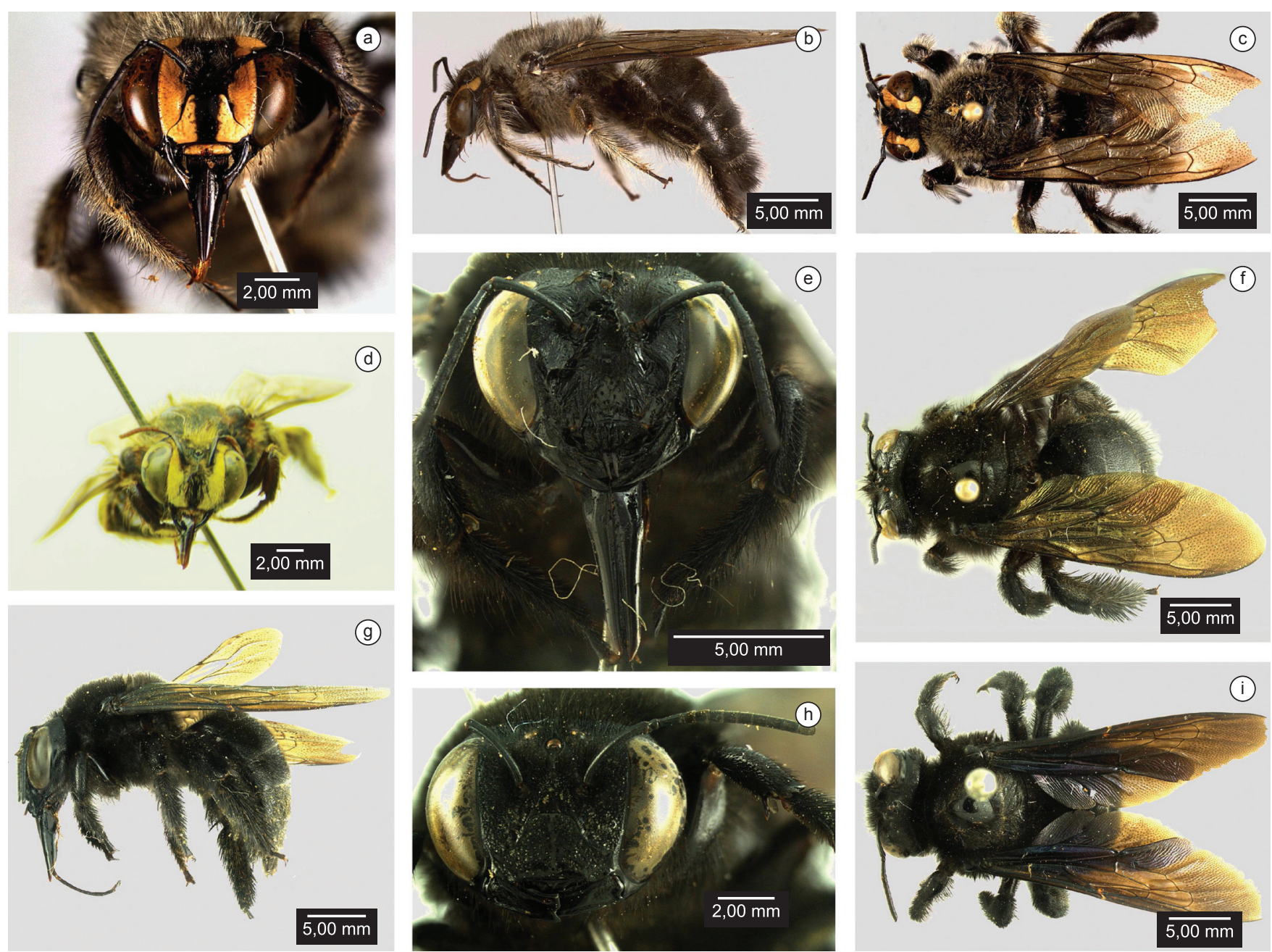

Figura 7. X. (Stenoxylocopa): (a, b, c) X. artifex (macho) vista frontal, lateral, dorsal; (d) X. nogueirai (macho) vista frontal; (e, f, g) X. artifex (fêmea) vista frontal, dorsal, lateral; (h, i) X. nogueirai (fêmea) vista frontal, dorsal. Escala para figuras b, c, e, f, g, i = 5,00 mm, figuras a, d, h=2,00 mm.

Figure 7. X. (Stenoxylocopa): (a, b, c) X. artifex (male) frontal, lateral and dorsal view; (d) X. nogueirai (male) frontal view; (e, f, g) X. artifex (female) frontal, dorsal and lateral view; (h, i) X. nogueirai (female) frontal and dorsal view. Scale for figures b, c, e, f, g, i = $5.00 \mathrm{~mm}$, figures a, $\mathrm{d}, \mathrm{h}=2.00 \mathrm{~mm}$. 